\title{
Zur Geschichte der Geowissenschaften im Museum für Naturkunde zu Berlin Teil 4: Das Mineralogische Museum der Universität Berlin unter Christian Samuel Weiss von 1810 bis 1856
}

\author{
Günter Hoppe ${ }^{1}$ \\ Mit 6 Abbildungen und 1 Tabelle
}

\section{Zusammenfassung}

Die Universitätsgründung in Berlin von 1810 war verbunden mit der Übernahme des Lehrbetriebes der aufgelösten Bergakademie, die nur noch in Form des Bergeleveninstituts bzw. Bergelevenklasse für die Finanzierung der Ausbildung der Bergeleven weiter bestand, sowie mit der Übernahme des von der Bergakademie genutzten Königlichen Mineralienkabinetts der preußischen Bergverwaltung als Mineralogisches Museum der Universität. Infolge des Todes von D. L. G. Karsten im Jahre 1810 erhielt der Leipziger Physiker und Mineraloge C. S. Weiss den Lehrstuhl für Mineralogie, den er bis zu seinem Tode 1856 innehatte. Weiss entwickelte die Lehre Werners, die die Mineralogie einschließlich Geologie umfasste, in kristallographischer Hinsicht weiter, während sich später neben ihm zwei seiner Schüler anderen Teilgebieten der Mineralogie annahmen, G. Rose der speziellen Mineralogie und E. Beyrich der geologischen Paläontologie. Der Ausbau der Sammlungen durch eigene Aufsammlungen, Schenkungen und Käufe konnte in starkem Maße fortgesetzt werden, auch zunehmend in paläontologischer Hinsicht, sodass das Mineralogische Museum für das ganze Spektrum der Lehre gut bestückt war. Der streitbare Charakter von Weiss verursachte zahlreiche Reibungspunkte.

\begin{abstract}
History of the Geoscience Institutes of the Natural History Museum in Berlin. Part 4

The establishment of the University in Berlin in 1810 resulted in the adoption of the teaching of the dissolved Bergakademie and of the royal Mineralienkabinett of the Prussian mining department, which was used by the Bergakademie before it became the Mineralogical Museum of the University. The Bergakademie continued to exist only as Bergeleveninstitut or Bergelevenklasse for financing the education of the mining students. The physicist and mineralogist C. S. Weiss was offered the chair of mineralogy after the death of D. L. G. Karsten 1810; he had the position to his death in 1856. Weiss developped the crystallographic part of the science of Werner which included mineralogy and geology. Two of his pupils progressed two other parts of mineralogy, G. Rose the speciel mineralogy and E. Beyrich the geological paleontology. The enlargement of the collections continued on large scale by own collecting, donations and purchases, also more paleontological objects, so that the Mineralogical Museum presented a good collection of the whole spectrum of the field. The pugnacious nature of Weiss resulted in many points of friction.
\end{abstract}

\section{Einleitung}

Die zwei ersten Teile dieser Artikelserie (Hoppe 1998, 1999) behandelten die Vorgeschichte des Mineralogischen Museums der Universität $\mathrm{zu}$ Berlin in zwei Stufen, die Zeit bis zur Gründung der Berliner Bergakademie im Jahre 1770 und die Entwicklung der Mineralogie an dieser Institution bis zur Gründung der Berliner Universität im Jahre 1810. Der dritte Teil (Hoppe 2000) ergänzte das Vorangegangene und beschäftigte sich speziell mit der Einführung der Kristallogra- phie in Berlin und dem damit eng verbundenen Werdegang des Leipzigers Christian Samuel Weiss vom Physiker zum Mineralogen und Kristallographen bis zu dessen Berufung als Direktor des Mineralogischen Museums anlässlich der Gründung der Universität.

Bereits vor der Universitätsgründung existierte im „Königlichen Mineralienkabinett“ ein ansehnlicher Fundus an Unterrichtsmaterialien, der auch angewandt wurde.

Der Umsicht des bedeutenden preußischen Ministers für das Berg- und Hüttenwesen Fried-

\footnotetext{
1 Wilhelm-Wolff-Str. 65, D-13156 Berlin; - Museum für Naturkunde, Institut für Mineralogie, Invalidenstr. 43, D-10115 Berlin, Germany.

Erhalten März 2001, angenommen Mai 2001
} 
rich Anton Freiherrn von Heinitz (Heynitz) (1725-1802) war es zu verdanken gewesen, dass für das Kabinett im Jahre 1801 zusammen mit anderen Institutionen ein besonderes Gebäude ${ }^{2}$ errichtet worden war, was dem Kabinett den Charakter eines Museums verlieh. Ein Besucherbuch weist dieses nach. Der Leiter der Einrichtung, der Mineraloge und Bergbeamte Dietrich Ludwig Gustav Karsten (1768-1810), der zur Berufung als Professor der Mineralogie anstand, verstarb jedoch während der Vorbereitungszeit der Universitätsgründung und es musste ein Nachfolger gefunden werden. Ein Gutachten des Berliner Geologen Leopold von Buch (1774-1853) bewirkte, dass Christian Samuel Weiss (1780-1856), der bereits bis dahin eng mit Karsten bei der Herausgabe der Übersetzung des kristallographisch orientierten Mineralogielehrbuchs des Franzosen René Just Haüy (Haüy $1801,1804 / 10$ ) zusammengearbeitet hatte, berufen wurde. So war ein günstiger Start der als Mineralogisches Museum der Universität eingegliederten Institution gesichert.

\section{Die Situation bei der Universitätsgründung}

Die Errichtung des Lehrstuhls für Mineralogie an der Berliner Universität ging einher mit der Aufhebung der Berliner Bergakademie. Trotzdem lief die Ausbildung von Bergeleven ${ }^{+}$weiter. nur wurde der Unterricht nunmehr an der Universität weitergeführt. Allerdings wurden sie dort aber nicht immatrikuliert. da der Bergbehörde die Aufsicht, Finanzierung und Koordinierung der Ausbildung von Bergeleven weiterhin oblag, was mit der Bezeichnung Bergeleveninstitut bzw. Bergelevenkasse umschrieben wurde ${ }^{5}$.

Der Übergang an die Universität erweiterte die Aufgaben, die der Lehrstuhl Mineralogie hatte, und befreite ihn von den Beschränkungen der auf die praktische Anwendung ausgerichteten Bergakademie. Diese Beschränkungen hatte allerdings bereits Karsten durch stärkere Einbeziehung von Chemie und Physik in die Mineralogie durchbrochen. Durch die Berufung von Weiss zum ordentlichen Professor der Mineralogie an der Universität wurde dies noch unterstrichen, da nun auch Kristallographie gelehrt wurde. Allerdings erhielt die Professur eine Doppelstellung, da sie aus zwei verschiedenen Fonds, dem der Universität und dem der Bergbehörde, finanzicrt wurde und Weiss sein Gehalt (1500 Taler jährlich) zu zwei Drittel aus der Bergelevenkasse und zu einem Drittel von der Universität erhielt. ${ }^{6}$ Außerdem erhielt die Bergbehörde Mitspracherechte bei der Nutzung des der Universität übergebenen Mineralienkabinetts. ${ }^{7}$ Unter diesen Bedingungen war Weiss am 25. 7. 1810 die Berufung von der Sektion für den öffentlichen Unterricht des preußischen Innenministeriums, deren Chef Wilhelm von Humboldt war, angeboten worden (GSTAB-13). Nach Klärung der Doppelstellung und nach Verständigung über den Kauf seiner privaten Mineralsammlung $^{8}$ nahm Weiss den Ruf am 27.8.1810 an (GSTAB-14, Bl. 236-7).

Bei der Eröffnung der Universität befand sich das Mineralogische Museum, wie das Kgl. Mineralienkabinett bereits im Vorlesungsverzeichnis der Universität für das Wintersemester 1810/11 genannt wurde, noch im bisherigen Lokal am

\footnotetext{
2 Das Gebäude lief unter der Bezeichnung ..Neue Münze", da im Untergeschoss Münzwerkstätten untergebracht waren. Zeitweilig befand sich bort auch die Bauakademie.

Das Fach Mineralogie wurde zur damaligen Zeit im weiten Sinn aufgefasst und ist dem heutigen Begriff Geologische Wissenschaften (.Geowissenschaften ") vergle ichbar.

${ }^{4}$ Bergeleven tnd Bergkadetten wurden für den Staatsdienst im Berg- und Hüttenwesen ausgebildet. Sie waren von der Zahlung von Gebühren befreit.

Für die weiteren. für die Ausbildung notwendigen naturwissenschaftlichen Fächer blicb es bei der bisherigen Regelung, die darin bestand. dass Honorarvereinbarungen zur Abhaltung entsprechender Lehrveranstaltungen mit geeigneten Personen (nun bevorzugt mit Universitätslehrern) abgeschlossen wurden. Einzelheiten dazu sind von Krusch (1904) zusammengestellt. Besondere bergbaukundliche Lehrveranstaltungen wurden erst einige Jahre später von der Bergbehörde, zum Teil unabhängig von der Universität. eingerichtet.

${ }^{6}$ Die Dotierung durch die Bergbehörde erscheint sehr reichlich. da Karsten neben seinem Einkommen als aktiver Beamter der Bergbchörde (zuletzt als deren Leiter) für den nebenamtlichen Unterricht nur 100 Taler und für die Leitung (..Aufsicht") des Kgl. Mineral enkabinetts 50 Taler als Honorar bezogen hatte. und Weiss kaum zu Leistungen in der Bergbehörde herangezogen wurde.

Das Mitspracherecht gerict sehr schnell in Vergessenheit, weil vereinbart war, dass alle Kosten für das nun offiziell „Mineralogisches Muscum der Universität" genannte Mineralienkabinett allein von der Universität getragen werden sollten.

${ }^{8}$ Weiss war nahe gelegt worden. sich von seiner privaten Sammlung zu trennen, da das Ministerium (wohl wegen Fehlens von Bestandsnaciweisen des Kabinetts) den von Karsten aufgestellten Grundsatz aufrecht erhielt. dass kein Aufseher eines öffentichen Kab netts ein eigenes glcicher Art haben solle. Weiss war zugcbilligt worden, seine Sammlung dem Staat zum Ankauf anzubieten. wenn er es für seinen Unterricht für nötig halten würde (GSTAB 14, BI. 239). Der Kauf kam nach Begutachtung des W'crtes durch den Mineralogen und Philosophen Henrik Steffens (1773-1845) zustande (Steffens 1844).
} 


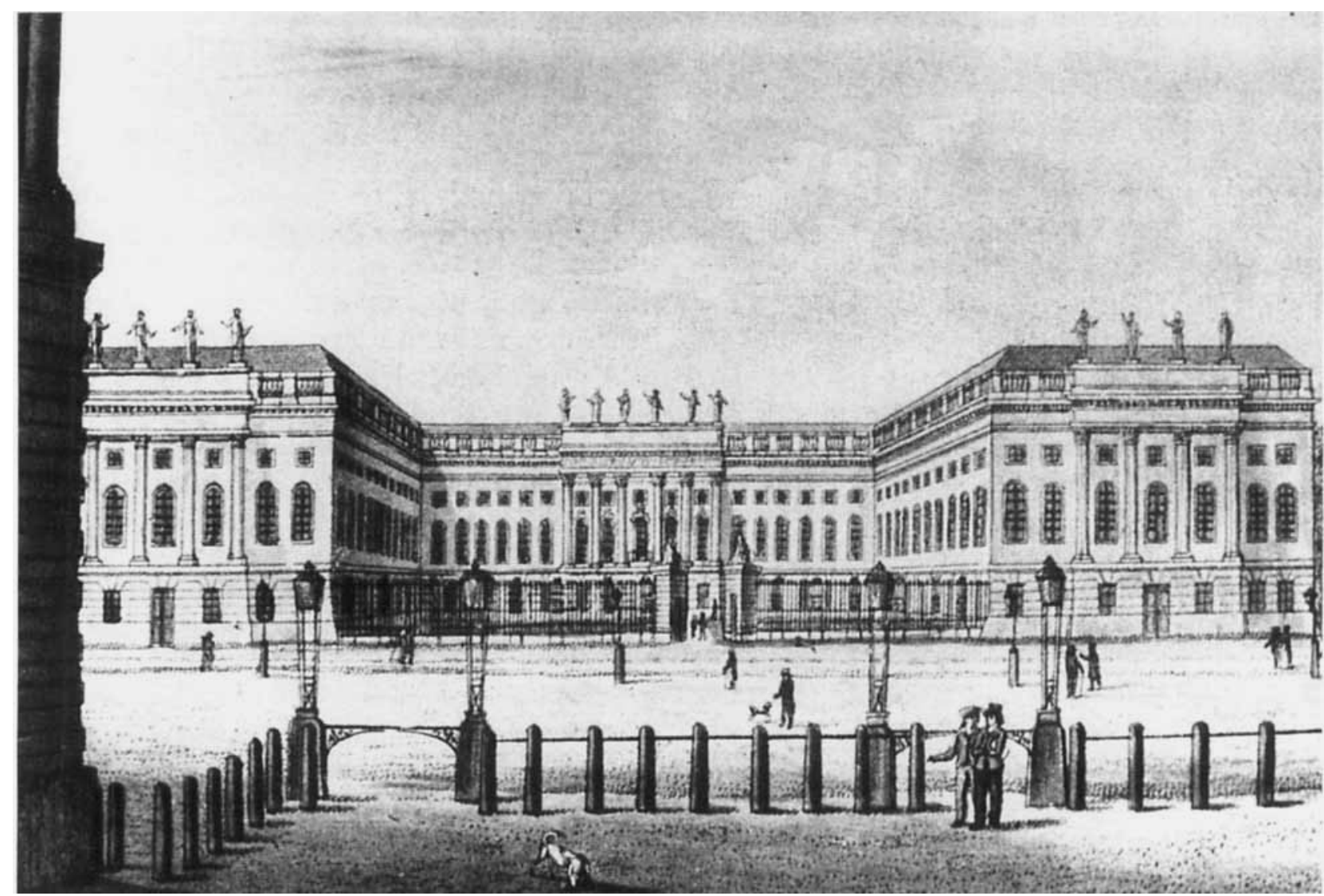

Abb. 1. Das Universitätsgebäude zu Berlin, Radierung von F. A. Schmidt und Forst, 1823. - Original Staatsbibliothek Preußischer Kulturbesitz Berlin.

Quartier des Mineralogischen Museums von 1814 bis 1889 im mittleren Geschoss der gesamten rechten (östlichen) Gebäudehälfte. - Dienstwohnung von C. S. Weiss im Kopfende des rechten Flügels.

Fig. 1. The building of the University in Berlin, etching by F. A. Schmidt and Forst, 1823. - Original in the Staatsbibliothek Preußischer Kulturbesitz Berlin.

The Mineralogical Museum was placed in middle level of the complete right (east) half of the building. - Official residence of C. S. Weiss in the front end of the right wing.

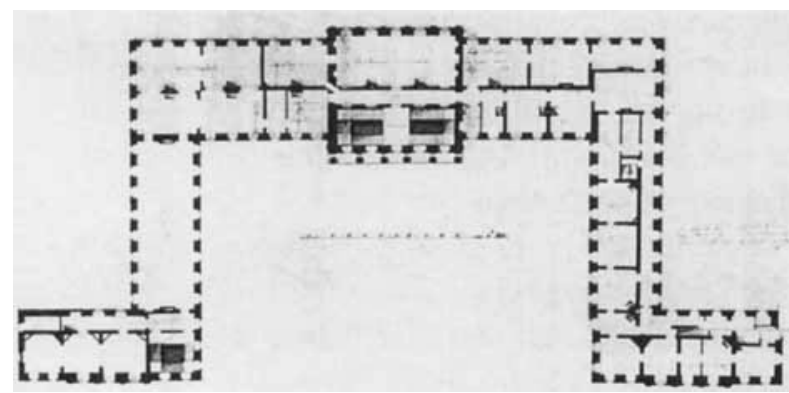

Abb. 2. Grundriss des mittleren Geschosses des Universitätsgebäudes aus dem Jahr 1819(?). - Original im Archiv der HU Berlin.

Fig. 2. Floor plan of the middle level of the University building in 1819(?). - Original in the Archiv of the Humboldt University Berlin.
Friedrichwerderschen Markt, in der so genannten Neuen Münze (Hoppe 1987a), etwa $600 \mathrm{~m}$ vom Universitätsgebäude entfernt. Jedoch war schon während der Vorbereitung der Universitätsgründung, noch unter Beteiligung von Karsten festgelegt worden, welche Räume das Mineralogische Museum in dem zum Hauptgebäude der Universität bestimmten Palais des Prinzen Heinrich erhält (GSTAB-15). Es war das mittlere Geschoss des gesamten östlichen Mittel- und Seitenflügels (Abb. 1 und 2) ${ }^{9}$. Dies bedeutete eine erhebliche Vermehrung des Raumes gegenüber dem Alten, durch bedeutende Schenkungen und Ankäufe völlig überfüllten Lokal (Hoppe 1999). Einen Teil dieser Räume erhielt Weiss als Dienstwohnung und zwar die am Kopfende des Flügels gelegenen Räume mit Ausblick nach Süden auf die Straße Unter den Linden. ${ }^{10}$ Aller-

\footnotetext{
${ }^{9}$ Die Räume im Seitenflügel hatten nicht die volle Geschosshöhe, da sich über ihnen ein Zwischengeschoss, das u. a. als Wohnungen des Universitätspersonals dienen sollte, befand, was sich aber an der Außenfront nicht bemerkbar machte.

${ }^{10}$ Es war eine sehr geräumige, ,splendide" Wohnung, wie Weiss seinem Bruder am 14.11.1810 schrieb (HASTB-3).
} 
dings zog sich der Einzug des Mineralogischen Museums noch Jahre hin. da die Räume des Palais nur allmählich frei wurden Der Umzug der Sammlungen konnte schließlich 1814 stattfinden. ${ }^{11}$ Noch länger besetzt blieb der im Zentrum des Mittelflügels direkt an das Auditorium maximum (später Aula) grenzende große Raum. der zunächst noch die für ein Museum vorgesehene Giustinianische Gemäldesammlung beherbergte.

\section{Die Mineralogie im ersten Jahrzehnt an der Universität Berlin}

Das erste Jahrzehnt der Universität war gezeichnet von den Unwägbarkeiten eines Neuanfangs in einer ungewissen Zeit. Noch wurde das Leben der Völker Europas durch die Eroberungspolitik Napoleons beherrscht und es kam schließlich durch dessen Feldzug in Russland zu einem Höhepunkt der kriegerischen Auseinandersetzung. der 1813 zum Befreiungskrieg Preußens mit groBer freiwilliger Beteiligung der Bevölkerung führte. Auch Berliner Studenten beteiligten sich unter Billigung durch den Senat der Universität daran. Die Stabilität der Universitätsgründung wurde jedoch nicht gefährdet. zumal sie vielerorts als Signal der Erneuerung durch eigene Kraft verstanden wurde. wenn auch die nach den Freiheitskriegen entstandene Burschenschaftsbewegung. besorders nach dem Attentat Sands auf Kotzebue, von der Regierung kritisch gesehen und bekämpft wurde.

Die Tätigkeit von Weiss wurde im Vorlesungsverzeichnis (AHUB-1) ${ }^{12}$ für das erste Semester der Universität mit den Worten angekündigt: ..Die Mineralogie lehrt Herr Prof. Weiss". Das Semester begann offiziell am 15.10.1810. Bald danach nahm Weiss seine Vorlesungstätigkeit auf. Einen Unterschied zwischen Bergeleven und den normalen. immatrikulierten Studenten machte Weiss bei seiner Mineralogievorlesung nicht. und las für die beiden Gruppen der Hörer ge- meinsam. Leider ist sehr wenig über die Anzahl der Hörer bekannt, insbesondere über die Anzahl der Bergeleven, die an der Universität nur als Gasthörer galten, und da die lückenhaft überlieferten Akten der Bergbehörde darüber kaum etwas hergeben.

Die Mineralogievorlesung ging über zwei Semester. Dazu heißt es im Vorlesungsverzeichnis des zwciten Semesters, des Sommersemesters (Beginn 25.3.1811): ,.Seinen im vorigen halben Jahr angefangenen mineralogischen und geognostischen Kursus vollendet Herr Prof. Weiss“. Wie die von einem Hörer angefertigte Nachschrift dieses zweiten Teils von 1811 ausweist ${ }^{13}$, setzte Weiss die Behandlung der Oryktognosie, d. h. der speziellen Mineralogie, fort, die er im Wintersemester begonnen hatte. Bei der Darstellung der einzelnen Minerale behandelte er deren Kristallformen, von ihm .,Struktur" genannt, sehr ausführlich und bezog sich dabei oft auf die Übersetzung des Lehrbuchs der Mineralogie des Franzosen R. J. Haüy (1801), an der er wesentlich beteiligt war. ${ }^{1+}$ In der Vorlesung kürzte er aber Haüys aufwendige Behandlung der Kristallformen der Minerale dadurch $a b$, dass er jeweils die Kristallflächen. die einer „Zone“ angehören, d. h. die eine gemeinsame Richtung haben, zusammenfasste. Dies ist besonders für solche Minerale sehr nützlich, die eine große Formenvielfalt zeigen. Interessanterweise griff er hiermit seinen Veröffentlichungen recht weit voraus, in denen er die Zonenbetrachtung erst Jahre später behandelte. ${ }^{15}$ Das Schwergewicht der Vorlesung lag auf den Kristallformen der Minerale. Dagegen wurden die übrigen Eigenschaften der Minerale nur kurz behandelt, wodurch Weiss deutlich zu erkennen gab, was ihm in der Mineralogie besonders wichtig war.

Bereits 1811 ergänzte Weiss seine zweisemestrige mineralogische Hauptvorlesung dadurch, dass er zusätzlich las: „Die Geognosie besonders und ausführlicher." Wie Werner betrachtete er die Mineralogie als das übergreifende Fach und schloss die Darstellung der Geognosie ${ }^{16}$ an sie

\footnotetext{
11 Der erst 184 vollzogene Imzug hat in späterer Zeit zur Vermutung Anlass gegeben, das Mineralogische Museum wäre erst zu diesem Zritpunkt entstanden. Hicrzu gibt es keine reale Grundlage.

" Dieser Hinweis auf die Vorlesungsverzeichnisse - AHUB-1 - entfällt im weiteren Text.

1: Diese Vorlesungsnachschrift (HHMFN-5) stammt ron Bückling. einem Sohn des um die Einführung der Dampfmaschine im preußischen Bergbau verdienten Karl Friedrich Bückling (1750-1812). wahrscheinlich von Adolf Bückling (1783-1830), der als Bergeleve bei Weiss hörte und auch in Freiherg studiert hat. Er wurde später Oberbergrat in Halle.

it Haüy 1804/16/10. - Uber das Zustandekommen der Übersetzung des Lehrbuchs des Franzosen R. J. Haüy (1801) durch D. L. G. Karsten C. S. Weiss und C. J. B. Karsten gibt der 3. Teil dieser Artikelseric Auskunft (Hoppe 2000)

Weiss beretherte die Kristallographie mit dem Begriff der Zone wesentlich und behandelte sie ab 1816 in Verötfentlichungen (Weiss $1819 \mathrm{a} .1819 \mathrm{~b} .1822 \mathrm{a}$ )

16 Weiss folgt: Werner auch in der Benennung dieses Faches. das dieser wegen ihrer Unvollkommenheit noch nicht als Gcologie. sondern vorläufig als Geognosic bezeichnete.
} 
an. $\mathrm{Ob}$ ihm Werner allerdings auch bei der Vorlesung über „Versteinerungskunde“, die Weiss nur einmal, im Sommersemester 1816, las, Vorbild war, ist fraglich, da Werner eine gleichnamige Vorlesung im Jahre 1799 vor der Studienzeit von Weiss gehalten hat. Vielmehr war es wohl die Geologievorlesung von G. Cuvier (1769-1832), die Weiss 1808 während seines Parisaufenthaltes gehört und als eine ,unterirdische oder geognostische Zoologie" und „ganz musterhaft und für mich höchst interessant und lehrreich" bezeichnet hatte. ${ }^{17}$.

Die Vorlesungen von Weiss wurden schon von seinen frühesten Hörern, zu denen Friedrich Fröbel (1782-1852), der spätere bekannte Pädagoge und Begründer des Kindergartens, und Karl Friedrich Klöden (1786-1856), der spätere Begründer der Berliner Gewerbeschule, gehörten, sehr gelobt. ${ }^{18}$ In dieses Lob wurde noch eine andere Vorlesung von Weiss ausdrücklich einbezogen, die dieser unter der Rubrik „Philosophische Wissenschaften" ankündigte. Es handelt sich um „Die philosophischen Principien der gesamten Natur-Wissenschaft". Weiss las sie erstmals im Sommersemester 1811 und variierte den Titel von Jahr zu Jahr etwas. Im Jahre 1814 las er „Philosophische Naturlehre“ und der Titel der letzten, 1817 gehaltenen Vorlesung dieser Art lautete „Die philosophischen Grundsätze der allgemeinen Naturlehre“. Weiss fußte bei seiner Vorlesung vor allem auf Immanuel Kant $(1724-1804)^{19}$ und fand dafür Verständnis bei dem Berliner Professor der Philosophie Johann Gottlieb Fichte (1762-1814), zu dem er ein gutes Verhältnis hatte. Er vermied absichtlich die Nennung des Wortes Naturphilosophie, wohl weil diese in Verruf gekommen war, u.a. durch das Wirken von Friedrich Wilhelm Joseph Schelling (1775-1854), von dem er sich distanzierte (Fischer 1963). Als dann der Philosoph Georg Wilhelm Friedrich Hegel (1770-1831) den Lehrstuhl für Philosophie in Berlin im Jahre 1818 er- hielt und selbst Vorlesungen über Naturphilosophie ankündigte, gab Weiss seine Vorlesung dieser Art auf

Über sein Spezialgebiet, die Kristallographie. las Weiss auch bereits von 1811 an. Diese Vorlesung war nicht für die Bergeleven gedacht, sondern für speziell Interessierte. Mit ihr stellte Weiss seine Forschungsergebnisse auf seinem Spezialgebiet vor, die jedoch teilweise, wie schon erwähnt, auch in seine Mineralogievorlesung einflossen. Der Titel der ersten Vorlesung dieser Art kennzeichnet sein Anliegen: „Kristallographie oder geometrische sowie mineralogisch-physikalische Theorie der Kristalle und der kristallinen Struktur". Später tritt diese Vorlesung unter "Krystallisationslehre“ oder „Mathemathische Krystallisationslehre“, auch einfach „Krystallographie" auf, schließlich begann er ab und an auch spezielle Themen daraus vorzutragen, die an seine Publikationen angelehnt sind.

Das Generalthema seiner Forschungen ist daraus zu erkennen. Er setzte seine in Leipzig begonnenen kristallographischen Arbeiten fort, mit denen er zuletzt mit seiner Leipziger Antrittsvorlesung (Weiss 1809) wesentliche Erkenntnisse bei der Auseinandersetzung mit den Ansichten des Franzosen R. J. Haüy erzielt hatte (siehe dazu Hoppe 2000). Im Jahre 1815 wurde dies von der Berliner Akademie der Wissenschaften durch seine Wahl zum ordentlichen Mitglied gewürdigt. Vor diesem Gremium zeigte er dann in seiner ersten Abhandlung, dass er mit seiner mathematischen Behandlung der Kristalle in der Lage ist, eine erste in sich geschlossene Systematik der Kristalle, basierend auf den Kristallachsen, aufzustellen. Auch wenn noch Unvollkommenheiten verblieben ${ }^{20}$, so stellte dies doch nach dem Urteil von P. Groth (1926: 70) einen Epoche machenden Fortschritt dar, da erstmals ein einheitlicher Überblick über das bis dahin herrschende Chaos der Kristalle geschaffen wurde. Diese Arbeit, die Weiss am 14.12.1815 in der

\footnotetext{
17 Weiss teilte dies seinen Geschwistern mit (HASTB-3, Brief vom 6. 7. 1808).

18 Fröbel war zu Weiss gekommen, um dessen Ansichten über die Kristalle, die Mineralkörper und die Erklärung der physikalischen Naturerscheinungen kennen zu lernen, und wurde nicht enttäuscht: „Die Vorträge, nach welchen ich mich gesehnt hatte, gaben meinem Geiste und Gemüthe in der Tat, was ich bedurfte und entwickelten [...] immer mehr meine Überzcugung von dem inneren nachweisbaren Zusammenhange aller cosmischen Entwicklung" (Fröbel 1862: 105). - Kloden urteilte: „Vier Jahre lang habe ich unausgesetzt alle seine Vorträge gehört über Mineralogie, Kristallographie, Geognosie, Petrefaktologie, philosophische Naturlehre etc., und bei keinem meiner Lehrer habe ich so viel gelernt, denn er führte tief in die Natur und tief in das Denken ein, keine andere Vorlesung ist mir so nützlich gewesen. Die Stunden, welche ich bei Weiss verlebte. gehören zu den bestangewandten meines Lebens“. (Klöden 1874: 326).

${ }^{19}$ Kant 1786. - Bereits im Jahre 1803 hatte Weiss in Leipzig über die Grundsätze der allgemeinen Naturwissenschaften gclesen und dazu ein Vorlesungsmanuskript mit dem Titel „Kants Metaphysische Anfangsgründe der Naturwissenschaft“ für das Sommersemester 1803 angefertigt. das erhalten geblieben ist (HASTB-6).

${ }^{20}$ Der wesentliche Fehler bestand in seiner Ansicht, dass die (nach heutiger Nomenklatur) monoklinen und triklinen Kristalle rechtwinklige Achsen besitzen.
} 
Akademie vortrug. erschien, wie auch alle seine späteren kristallographischen Arbeiten. in den Abhandlungen der Akademie der Wissenschaf-

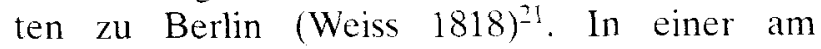
22. 10. 1818 vorgetragenen Arbeit zeigte er. dass die von ihm eingeführten Symbole für die einzelnen Kristallflächen geeignet sind, die Zugehörigkeit der Flächen zu den verschiedenen Zonen des Kristalls abzulesen (Weiss 1820). was einen weiteren Schritt der Vervollkommnung seiner Kristallographic einleitete..$^{22}$

Die Lehre der Mineralogie umfasste natürlich auch entsprechenden Anschauungsunterricht an Originalobjekten. Da das zum Mineralogischen Museum der Universität erklärte Königliche Mineralienkabinet sich anfangs noch am Werderschen Markt befand, dürften die mineralogischen Übungen. dic Weiss in den Jahren 1812 bis 1814 ankündigte, dort abgehalten worden sein. während die Vorlesungen im Universitätsgebäude stattfanden. Nach dem Umzug im Jahre 1814 kündigte Weiss keine gesonderten Übungsstunden mehr an. Bci dem Umzug war Weiss übrigens nicht anwesend, da er verspätet nach dem Semesterbeginn von der Ferienreise zurückgekommen war. Dies brachte ihm eine Rüge vom Ministerium ein, außerdem noch eine zweite Rüge. weil er gegen die Durchführung des Umzuges in seiner Abwesenheit und gegen die vorläufige Aufstellung der Schränke in seiner Wohnung protestierte, deses Mal wegen ...ungehörigen Tones" gegenüber dem Ministerium³.

Für die Herstellung der Ordnung und der Einrichtung des Mineralogischen Museums stand Weiss zunächst nur ein ..Aufwärter" als Hilfskraft zur Verfügung. Er konnte aber noch 1814 außerdem einen ..Gehilfen“ einstellen. Für zwei Jahre war es sein Schüler F. Fröbel (1782-1852). der für seine freiwillige Teilnahme am Freiheitskrieg vom Ministerium wegen seiner Mittellosigkeit die Zusicherung einer Anstellung nach dem Kriege crhalten hatte, was nach Antrag von Weiss und Aufstellung einer Instruktion realisiert wurde (GSTAB-16. Bl. 118-120). Ihm folgte
1816 (bis 1821) Inspektor Hoffmann, ein ehemaliger Leutnant. für dessen Versorgung ebenfalls das Ministerium aufkommen musste. Hoffmann war jedoch wegen geringer Sachkunde für Weiss keine volle Hilfe, zumal es Weiss an Anleitung fehlen ließ und Hoffmann infolge niedrigen Gehaltes $^{2+}$ gleichgültig wurde. So klagte Weiss im Jahre 1816 in einem Brief an seinen Freund, den dänischen Physiker H. C. Örsted (1777-1851) (Hoppe 1982: 251), dass ihn die Arbeit im Kabinett ${ }^{25}$ sehr ,vom Schriftstellern abhalten“ würde.

Weiss sorgte aber dafür, dass die Sammlungen durch neues Material vervollständigt wurden und sammelte auf seinen Reisen auch selbst. So brachte er 1814 aus den Alpen unter anderem ..Bavenoer Feldspathkrystalle, meine Lieblinge“ mit. Diese Feldspatzwillinge verlangten „eine nicht geringe Übung, um sie richtig zu entziffern" (Weiss 1815). Neben Mincralen dürfte er sich auch um Versteinerungen bemüht haben, jedoch sind Eigenfunde von Weiss für die Frühzeit anscheinend nicht zu belegen (Dietrich 1960: 256). In den Sammlungen hat sich aber bereits damals paläontologisches Material befunden (Hoppe $2000)^{26}$. Im Jahr 1812 konnte ein Teil der Mineralsammlung des Berliners F. W. Siegfried ${ }^{27}$ gekauft werden und im Jahre 1814 gab es die wertvolle Schenkung einer Sammlung niederrheinischer Gesteine durch den Arzt K. W. Nose (17531835). der sich höchst intensiv der mineralogischpetrographischen Erforschung dieser Gesteine gewidmet und darüber mehrfach ausführlich publiziert hatte (zuletzt: Nose 1808). Ähnlich der Meinung A. G. Werners lehnte er eine vulkanische Deutung der Entstehung dieser Gesteine ab. Nose hatte diese Sammlung für Bonn bestimmt gehabt (Langer 1983), gab sie dann aber nach Aussprachen mit Weiss, der ihn 1812 besuchte, nach Berlin. In einem Brief vom 2.8.1814 an A. G. Werner (SBAF-4) berichtete Weiss von dieser Schenkung. ${ }^{28}$ Gegenüber diesen Erwerbungen war Weiss für die Abgabe an Material, wie es für die 1813 gegründete Universität Breslau verlangt wurde. nicht zu gewinnen (Raumer 1866).

\footnotetext{
21 Die Abhandlungen der Berliner Akademic der Wissenschaften erschienen oft mit mehrjähriger Verspätung.

Die Weissschen Symbole wurden später von dem englischen Mineralogen W. H. Miller (1801-1880) in reziproker Form verwendet. Es sir d die sog. Millerschen Indizes. die noch heute zur Kennzeichnung der Kristallflächen in Gebrauch stehen.

$\because$ GSTAB-16. B1. 125-132. - Der ZusammenstoB mit dem Ministerium sollte nicht der Einzige bleiben.

it Hoffmann richtete 1818 und 1821 erfolglose Eingaben an das Ministerium (GSTAB-17, B1. 57-74).

$\therefore$ Weiss verwindte die offizielle Bezeichnung Mineralogisches Museum nur selten.

2h Hicrfür war sogar ein besonderer Raum am Ende des östlichen Hauptflugels des Universitätsgebäudes vorgesehen,

Der Rendant und Mineralliebhaber W. F. Siegtried (1734-1809) war Milgründer der Gesellschaft naturforschender Freunde zu Berli 1 und verwalter von deren naturhistorischen Sammiungern.

2s Dort heißt is weiter: Dic Sammlung schließt sich .. an die Sammlungen aus Auvergne am direktesten an. und wird neben dieser in unserm Kabinct einen schönen Platz einnehmen”.
} 
Tabelle 1 Schüler von Christian Samuel Weiss (in chronologischer Reihenfolge)

\begin{tabular}{|c|c|c|c|}
\hline Name & Lebensdaten & Studium bei Weiss & spätere Tătigkeit \\
\hline Chamisso, Adelbert von & $1781-1838$ & $1812-[1815]$ & Naturforscher und Dichter \\
\hline Fröbcl, Friedrich & $1782-1852$ & $1812-1814$ & Vorschulpädagoge/Kindergarten \\
\hline Klöden, Karl Friedrich & $1786-1856$ & $1814-1817$ & $\begin{array}{l}\text { Pädagoge, Direktor der Gewerbe- } \\
\text { schule in Berlin }\end{array}$ \\
\hline Oeynhausen, Karl von & $1795-1865$ & als Bergeleve vor 1817 & $\begin{array}{l}\text { Bergbeamter, zuletzt Berghauptmann } \\
\text { in Dortmund }\end{array}$ \\
\hline Hotfmann, Fricdrich & $1797-1836$ & $\begin{array}{l}\text { (nach Studium in Göttingen) } \\
1820-1\end{array}$ & $\begin{array}{l}\text { Geologe, } 1833 \text { a. o. Prof. für } \\
\text { Mineralogie an der Univ. Berlin }\end{array}$ \\
\hline Rose, Gustav & $1798-1873$ & $\begin{array}{l}1817-1820, \text { Diss. } 1820 \\
\text { (erste naturwissenschaftliche } \\
\text { Promotion an der Universität Berlin) }\end{array}$ & $\begin{array}{l}\text { Mineraloge, } 1826 \text { a. o. Prof., } \\
1839 \text { o. Prof. für Mineralogie } \\
\text { an der Univ. Berlin }\end{array}$ \\
\hline Neumann, Franz Ernst & $1798-1895$ & $\begin{array}{l}\text { nach Theologiestudium ab } 1819 \text {, } \\
\text { Diss. } 1826\end{array}$ & $\begin{array}{l}\text { Kristallograph und Physiker. Prof. für } \\
\text { Physik und Mineralogie in Königsberg. }\end{array}$ \\
\hline $\begin{array}{l}\text { Kupfer (Kupffer), } \\
\text { Adolf Theodor }\end{array}$ & $1799-1865$ & $1816-1819$ & $\begin{array}{l}\text { Mineraloge und Geophysiker, Prof. in } \\
\text { Kasan, dann Akademiker St. Petersburg }\end{array}$ \\
\hline $\begin{array}{l}\text { Wackernagel, } \\
\text { Eduard Philipp }\end{array}$ & $1800-1877$ & $\begin{array}{l}\text { (nach Studium in Breslau } \\
\text { und Halle) } 1824\end{array}$ & $\begin{array}{l}\text { Mineraloge, Pädagoge. } \\
\text { Kirchenliedforscher }\end{array}$ \\
\hline Dechen, Heinrich von & $1800-1889$ & als Bergeleve $1818-1820$ & $\begin{array}{l}\text { Bergbeamter, daneben } 1834-1841 \text { a. o. } \\
\text { Prof. d. Geologie an der Univ. Berlin, } \\
\text { dann Berghauptmann in Bonn }\end{array}$ \\
\hline $\begin{array}{l}\text { Gumprecht, } \\
\text { Thaddäus Eduard }\end{array}$ & $1801-1856$ & ab 1832 & $\begin{array}{l}\text { Privatdozent für Geologie und } \\
\text { Geographie an der Univ. Berlin }\end{array}$ \\
\hline Kayser, Gustav Eduard & $1803-$ & bis 1832 , Diss. 1834 & Pädagoge in Landeshut, Schicsien \\
\hline Carnall, Rudolf von & $1804-1674$ & $\begin{array}{l}\text { als Bergeleve } 1823 \text {; } \\
\text { Dr. phil. h. c. } 1855\end{array}$ & $\begin{array}{l}\text { Bergbeamter, u. a, in Berlin (Dozent d. } \\
\text { Bergbaukunde), ab } 1855 \text { in Breslau }\end{array}$ \\
\hline Karsten, Hermann & $1809-1877$ & $\begin{array}{l}1827-1829 \text { (kristallogr. Diss. } 1829 \\
\text { in Rostock) }\end{array}$ & $\begin{array}{l}\text { Prof. der Math. und Mineralogie } \\
\text { Rostock }\end{array}$ \\
\hline $\begin{array}{l}\text { Quenstedt, Friedrich } \\
\text { August }\end{array}$ & $1809-1899$ & $1830-1833$, Diss. 1836 & $\begin{array}{l}\text { Mineraloge, Geologe und Paläontologe, } \\
\text { Prof. an der Univ. in Tübingen }\end{array}$ \\
\hline Troschel, Franz Hermann & $1800-1882$ & 1832 & $\begin{array}{l}\text { Zoologe und Paläontologe, Prof. an der } \\
\text { Univ. in Bonn }\end{array}$ \\
\hline Ewald, Julius & $1811-1891$ & $\begin{array}{l}\text { nach } 1830,4 \text { Semester, } \\
\text { Diss. } 1837\end{array}$ & $\begin{array}{l}\text { Kristallogr. Diss., Geologe und } \\
\text { Paläontologe }\end{array}$ \\
\hline $\begin{array}{l}\text { Leichhardt, Friedrich } \\
\text { Wilhelm Ludwig }\end{array}$ & $1813-1848$ & $1834-1837$ & Geologe, Australienforscher ab 1841 \\
\hline $\begin{array}{l}\text { Rammelsberg, } \\
\text { Karl Friedrich }\end{array}$ & $1813-1899$ & $\begin{array}{l}\text { ab 1834-1837 } \\
\text { (chemische Diss. 1837) }\end{array}$ & $\begin{array}{l}\text { Chemiker und Mineraloge, Prof. am } \\
\text { Gewerbeinstitut an der Universität Berlin }\end{array}$ \\
\hline $\begin{array}{l}\text { Girard, Karl } \\
\text { Adolf Heinrich }\end{array}$ & $1814-1878$ & ab 1835, Diss. 1840 & $\begin{array}{l}\text { Prof. der Mineralogie und Geologie } \\
\text { an der Universität Halle }\end{array}$ \\
\hline $\begin{array}{l}\text { Emmrich, Hermann } \\
\text { Friedrich }\end{array}$ & $1815-1879$ & 1835-1838, Diss. 1839 & $\begin{array}{l}\text { Geologe und Paläontologe, Pädagoge in } \\
\text { Meiningen }\end{array}$ \\
\hline $\begin{array}{l}\text { Beyrich, } \\
\text { August Heinrich Ernst }\end{array}$ & $1815-1896$ & $1831-1834,1836 / 7$, Diss. 1837 & $\begin{array}{l}\text { Geologe und Paläontologe, } 1846 \text { a. o. Prof., } \\
1865 \text { o. Prof. an der Universität Berlin }\end{array}$ \\
\hline $\begin{array}{l}\text { Karsten, } \\
\text { Gustav Wilhelm Hermann }\end{array}$ & $1817-1908$ & vor 1843 & $\begin{array}{l}\text { Botaniker, Geologe, Suidamerikareisen, } \\
\text { Prof. d. Botan. Berlin, dann Prof. Wien }\end{array}$ \\
\hline Roemer, Carl Ferdinand & $1818-1891$ & 1840-1842 (zuvor Göttingen) & $\begin{array}{l}\text { Paläontologe, Prof. der Mineralogie } \\
\text { der Universität Breslau }\end{array}$ \\
\hline Kokscharow, Nicolai von & $1818-1893$ & 1844 & $\begin{array}{l}\text { Berging. u. Mineraloge, Prof. u. Direktor } \\
\text { des Berg-Institutes in St. Petersburg }\end{array}$ \\
\hline Websky, Martin & $1824-1886$ & 1846-1847 als Bergeleve & $\begin{array}{l}\text { Bergbeamter, dann Prof. d. Mineralogie } \\
\text { Univ. Breslau, ab } 1973 \text { Univ. in Berlin }\end{array}$ \\
\hline Wciss, Christian Ernst & $1832-1901$ & $\begin{array}{l}\text { "letzter" Schüler von C. S. Weiss, } \\
\text { (kristallogr. Diss. } 1860 \text { in Halle) }\end{array}$ & $\begin{array}{l}1872 \text { Landesgeologe und Prof. an der } \\
\text { Bergakademie in Berlin }\end{array}$ \\
\hline
\end{tabular}


Für Ankäufe stand dem Mineralogischen Museum ab 1816 der bedeutende Betrag von 1000 Talern zur Vertügung. Darüber hinaus konnten auch Sondermitel erwirkt werden. Ein solcher Fall trat ein. als nach dem Tode des berühmten Chemikers Martin Heinrich Klaproth am 1.1.1817 dessen wertvolle Mineralsammlung von den Erben angeboten wurde. Weiss schätzte ihren Wert sehr hoch ein, da sie die Originale zu den von Klaproth in großer Zahl angefertigten Mineralanalysen und $\mathrm{zu}$ seinen Elemententdeckungen enthielt (GSTAB-18). Die Sammlung wurde dann für den geforderten hohen Preis von 12000 Talern gekauft (Hoppe 1989).

Mit dem Unzug in das Universitätsgebäude wurde die Verwendung des zuvor geführten Besucherbuches, das noch bis 1813 Eintragungen enthält (Hoppe 1999), beendet. Spätere Klagen lassen erkennc n. dass die öffentliche Nutzung des Mineralog schen Museums im Universitätsgebäude geringer als im Königl. Mineralienkabinett im Münzgebäude gewesen ist, wo Karsten oft selbst Führangen gemacht hatte. Der Zugang $z u$ der Sammlung war für Studierende nur für wenige Stunden wöchentlich gestattet. da der Eingang zu din Räumen des Mineralogischen Muscums direkt neben dem Auditorium maximum lag und Weiss fürchtete. dass es in den Unterrichtspauser großen Andrang mit schädlichen Folgen geben könnte.

Weiss hatte besonders in den ersten Jahrzehnten seiner Tätigkeit in Berlin zahlreiche Schüler. denen er, wenn sie bei ihm promovieren wollten. vorwiegend kıistallographische Dissertationsthemen stellte. In vorstehender Übersicht (Tab. 1). die über die ganze Wirkungszeit von Weiss in Berlin reicht. sind die wichtigsten Schüler von Wciss zusammengestellt (teilweise nach $\mathrm{T}$. Liebisch in Lenz 1910: III. 311).

Über seine unmittelbaren Obliegenheiten hinaus stellte sich Weiss auch für Universitätsämter zur Verfügung und amtierte als Dckan der Philosophischen Fakultät bereits 1811/2, als Rektor $1818 / 19^{29}$. Sein entschiedenes Auftreten machte ihn hicrfür geeignet. Als Rektor setzte er sich für Studenten ein. die eine Nachtmusik zu Ehren von F. J. Jahn aufgeführt hatten. der der Regierung durch sein an die Burschenschaftsbewegung anknüpfendes Turnwesen unliebsam geworden war. Dadurch wurde eine gerichtliche Verfolgung der Studenter verhindert. was der Senat nachträglich billigte 1818/19 (Lenz 1910: 2. Bd.. S. 46). Vor solchen und anderen Auseinanderset- zungen schreckte Weiss durchaus nicht zurück. Allerdings liefen diese nicht immer günstig für ihn aus. Ein solcher Fall ereignete sich innerhalb des Rates der Philosophischen Fakultät im Jahre 1817. als der Sohn des 1814 verstorbenen Philosophen Fichte mit einer Dissertation auftrat, von der Weiss behauptete, sie wäre eine Schrift des Vaters des Promovenden. Nach einer Untersuchung des Falles wurde diese Anschuldigung als ..ungeheuerlich" zurückgewiesen (Lenz 1910: 1. Bd.. S. 594).

Am Ende dieses Kapitels soll noch die Einstellung von $\mathrm{C}$. S. Weiss zu Preußen charakterisiert werden. Hierfür sind seine Worte in einem Brief

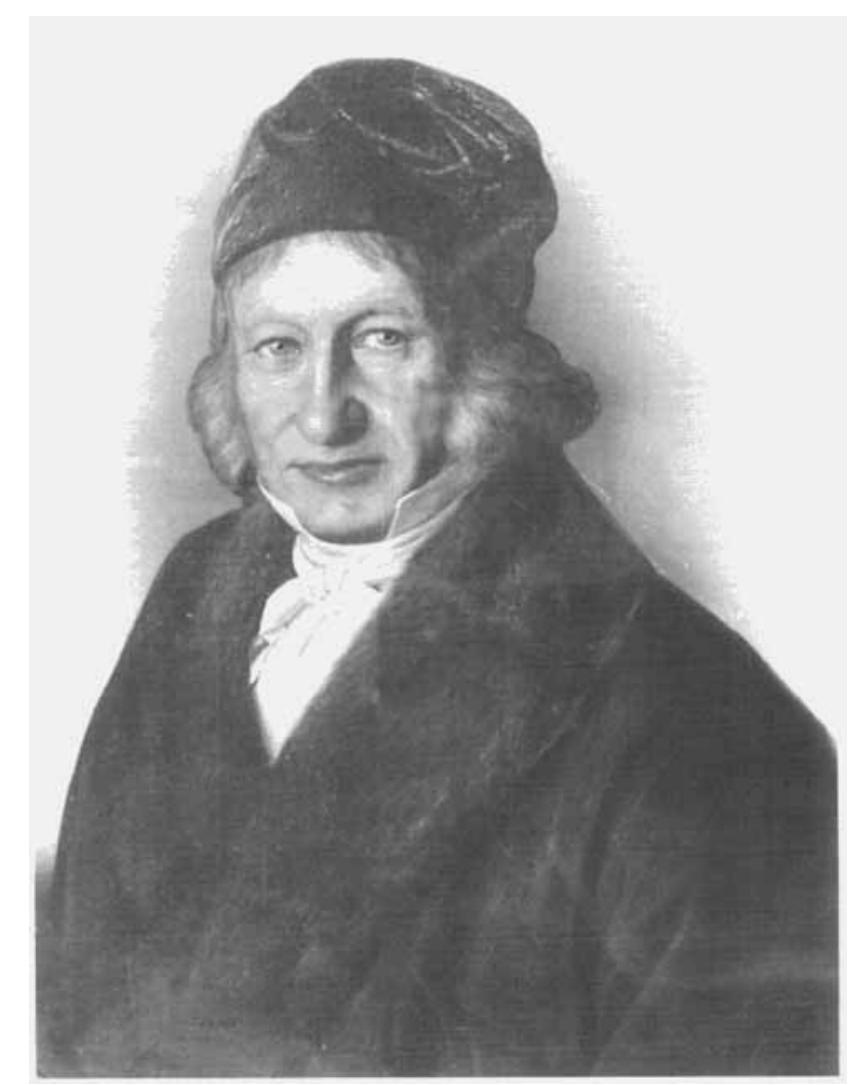

Ahb. 3. Christian Samuel Weiss (1780-1856), Porträt in höherem Lebensalter. - Fotografische Wiedergabe eines Ölgemäldes, das sich im Mineralogischen Institut der Technischen Hochschule Berlin-Charlottenburg befand. Das Original ging wahrscheinlich im 2. Weltkrieg durch die Zerstörung des Gebäudes verloren. - Foto im Besitz des Mineralogischen Institutes der Humboldt-Universität zu Berlin. Eine andere Wiedergabe des Originals befindet sich bei Schuster (1922. S. 89)

Fig. 3. Christian Samucl Weiss (1780-1856) in late age. Fotografic reproduction of an oil painting, which was in the department of mineralogy of the Technical University BerlinCharlottenburg. The original was probably lost during World War II with the destruction of the building. - Foto in the department of mineralogy of the Humboldt University Berlin. Another reproduction of the original was published by Schuster (1922: 89)

\footnotetext{
Weiss war später wiederum 1822/3. 1827/8 und 184.5/6 Dekan sowie 1832/3 Rektor
} 
an Werner geeignet, den er am 24.5. 1813 während des Befreiungskrieges, unmittelbar nach der am 20./21.5. 1813 stattgefundenen Schlacht von Bautzen, die für Napoleon noch günstig ausgegangen war, geschrieben hat, 5 Monate vor der entscheidenden Völkerschlacht bei Leipzig. In diesem Brief heiBt es (SBAF-4):

..Meine Empfindungen in diesen Tagen und Stunden großer zweifelnder zögernder unsicherer Erwartungen will ich Ihnen nur mit wenigem auszudrücken versuchen. Es wäre mir sehr hart, von einer entschiedenenen Nicderlage der Unsrigen ich meine der Preußen und Russen - zu hören. Allein dahin, glaube ich, werde ich nicht zu bringen seyn, dass ich es wünschen sollte, in dieser Zeit großer Entscheidung anderswo als hier gewesen zu seyn. Ich wäre unaussprechlich unglücklich und elcnd gewesen, hätte ich das in Sachsen, und dort in öffentlichem Amte, erleben sollen. Ich habe mich aus der Fülle meiner tiefsten Überzeugung glücklich gepriesen, jetzt diesem Theile Deutschlands anzugehören: und kein $\mathrm{Au}-$ genblick hat darin mich wankend gesehen."

Insgesamt gesehen, war das erste Jahrzehnt der neuen Universität ein guter Anfang für Weiss (Abb. 3) und das Mineralogische Museum. Allmählich verblasste aber die Neuheit und machte einer nüchterneren Alltagssituation Platz. Wie diese aussah, sollte sich sehr bald zeigen.

\section{Die Entwicklung in den Jahren von 1820 bis 1840 - C. S. Weiss und G. Rose}

Dem Staatskanzler v. Hardenberg ${ }^{30}$ war zu Ohren gekommen, dass in den Berliner Museen von den "Aufwärtern" Trinkgelder für den Eintritt und das Zeigen von Objekten genommen wurden, weshalb auch die Universitätsmuseen überprüft wurden, um diese Unzulänglichkeit abzustellen. Im Mineralogischen Museum fand der für die Universität eingesetzte Regierungsbevollmächtigte, der Geheime Oberregierungsrat J. Schulze, nach seinem Bericht vom 3. 12.1820 an den Minister v. Altenstein ${ }^{31}$ (GSTAB-17, Bl. 45-8) eine andere Unzulänglichkeit, und zwar eine zu geringe, ganz unbefriedigende „Gemeinnützigkeit" im
Verhältnis zu der guten Ausstattung mit Sammlungen, die darin bestand, dass dic Sammlungen infolge sehr geringer Zahl von Glasschränken nur unter persönlicher Aufsicht des Direktors Weiss an wenigen Stunden pro Woche besucht werden konnten. Zur Behebung dieses Zustandes schlug er vor, in den Räumen des Mittelflügels einen mit Glasschränken ausgestatteten Ausstellungsteil einzurichten und anstelle des derzeitigen, aber ungeeigneten Gehilfen Inspektor Hoffmann, einen voll ausgebildeten Gehilfen. oder einen zweiten Professor einzustellen. Die Mittel für die Anschaffung von Glasschränken wären zu gewinnen, wenn die bei der dringend notwendigen Inventarisierung der Bestände ..in gewiss sehr großer Masse" anfallenden Dubletten verkauft würden. Der Minister v. Altenstein übernahm die Vorschläge im Wesentlichen. Als geeigneten Gehilfen empfahl er dem Staatskanzler einen befähigten Schüler von Weiss. Gustav Rose (1798-1873), und beantragte zu dessen Förderung ein Stipendium für eine Reise nach Schweden und Norwegen, um die Rose gcbeten hatte (GSTAB 19). ${ }^{32}$ Die Einstellung Roses verzögerte sich noch, da seine Reise vom Februar bis zum Herbst 1821 dauerte. Auf ihr besuchte Rose Erzgruben und andere Mineralvorkommen und studierte in Stockholm, wo sich bereits Mitscherlich und sein Bruder Heinrich befanden, die bei Berzelius zu hoher Vollkommenheit entwickelte Lötrohrmethode.

In Berlin wurde inzwischen zur Überbrückung der Abwesenheit Roses der Student F. E. Neumann, ebenfalls ein sehr befähigter Schüler von Weiss, im Mai 1821 für ein Jahr als Gehilfe eingestellt (GSTAB 17, Bl. 87-8), der jedoch bereits nach 6 Wochen aus familiären Gründen wieder ausschied. ${ }^{33}$

Im Frühjahr 1822 verlangte das Ministerium von Weiss einen Bericht über getroffene Maßnahmen zur Erfassung und Veräußerung von Dubletten und zur Katalogisierung der Samm-

\footnotetext{
3 Karl August Fürst v. Hardenberg (1750-1822) war bis 1821 preußischer Staatskanzler.

.1 Karl Freiherr von Stein zum Altenstein (1770-1840), war seit 1817 preußischer Minister für geistliche. Unterrichts- und Medizinal-Angelegenheiten.

${ }_{32}$ Die Förderung von Gustav Rose stand in weiterem Zusammenhang mit den Bemühungen des Ministers v. Altenstein. den berühmten Stockholmer Chemiker J. J. Berzelius als Nachfolger für den 1817 verstorbenen Professor der Chemie an der Berliner Universität, M. H. Klaproth, zu gewinnen. Da dieser jedoch bei seinem Besuch in Berlin im August 1819 ablehnte und E. Mitscherlich zur Berufung empfahl, weil er von diesem gerade durch die Entdeckung der später Isomorphic genannten Formengleichheit chemisch verschiedener Kristalle außerordentlich becindruckt war, wurde Mitscherlich vor seiner endgültigen Berufung noch zu weiterer Vervollkommnung nach Stockholm zu Berzelius gesandt. Sehr wahrscheinlich war es v. Altenstein dabei zu Ohren gekommen, dass Rose an der Entdeckung Mitscherlichs nicht unwesentlich beteilig1 war (Hoppe 2001).

33 Neumann blieb jedoch mit Weiss in engem Kontakt und konnte dessen Kristallographie durch Projektionsmethoden ergänzen (Neumann 1823). Weiss gestattcte ihm auch, Vorträge zu halten und riet ihm, sich um eine Anstellung zu bcwerben. Daraufhin wurde er nach seiner Promotion (Neumann 1826, Biermann 1960) als Professor nach Königsberg berufen (Neumann 1904) und entwickelte sich dort zu einem bedeutenden Physiker.
} 
lungsbestände, auf den Weiss am 16.4.1822 in einem höchst ausführlichen Schreiben antwortete (GSTAB-17, B।. 120-127). Hierin versuchte er, das Ministerium zu bewegen, beide Forderungen fallen zu lassen. Er sah einen grundsätzlichen Unterschied zwischen mineralogischen und zoologischen Objekten im Hinblick auf ihre Einstufung als Dubletten, weshalb er die im Zoologischen Museum geübte Praxis des Dublettenverkaufs $^{34}$ für das Mineralogische $\mathrm{Mu}$ seum ablehnte. Die geforderte Katalogisierung charakterisierte er höchst drastisch als die „allertrübseligste und nutzloseste Scheinarbeit". Das Ministerium zeigte sich davon nicht beeindruckt und blieb bei den Forderungen (GSTAB17, Bl. 130-4). Immerhin sah man aber ein, dass die Einstellung eines gut ausgebildeten Gehilfen, dem Teilaufgaben übertragen werden können. notwendig wurde.

Die Einstellung Roses als Gehilfe erfolgte dann zum 1. 0. 1822 (GSTAB-17, Bl. 160-3). Da ,in wissenschaftlicher Hinsicht an ihn größere Ansprüche" gemacht wurden (GSTAB-20. Bl. 1), erhielt er das doppelte Gehalt seines Vorgängers Hoffmann. Der von Weiss vorgelegte Instruktionsentwurf (GSTAB-17. Bl. 156-7) schrieb an Pflichten firr Rose u. a. die Erarbeitung von Katalogen vor, auch das Verbot der selbstständigen Sammlungsbenutzung. Letzteres strich das Ministerium und setzte dafür ein:

.Da das Ministerium wünscht. dass der Doktor Rose sich zur Lehre der Mineralogie ausbilden und somit als Gelehrter für diese Wissenschaft wirksam seyn möge. so wird ihm zur Verfolgung seiner de fallsigen Zwecke die selbstständige Benutzung des Königlichen Mineralogischen Museums gestattet."

Zwei Jahre später legte Rose nach einer Mahnung vom Ministerium am 9.8.1823 als ersten Katalog den der „Prachtstücke“ vor. AnschlieBend durfte Rose nochmals eine Reise zu seiner Weiterbildung antreten, die ihn von Oktober 1823 bis August 1824 nach Paris und London führte (GSTAB-21, Bl. 20, 30, 54-7)..$^{35}$

In der Zeit der Gehilfentätigkeit Roses gab es zahlreiche Be:standserweiterungen der Sammlung durch Tausch. Geschenke und Kauf. Nur die wichtigsten davon können hier erwähnt werden, an erster Stelle die Sammlung, die Rose von seiner Reise nach Schweden und Norwegen mitbrachte, in der auch Material enthalten war, das er von seinem Bruder Heinrich und von Berzelius erhalten hatte. Im Jahre 1820 konnten sibirische Minerale und Gesteine aus der Sammlung des Bergbeamten F. A. A. Eversmann (GSTAB 17. B1. 25-6) gekauft werden, sowie eine Sammlung schwedischer Minerale von Graf Lobo (Köpke 1860: 279). Auch von Schülern von Weiss kam Material, so von H. v. Dechen und K. v. Oeynhausen, das diese in England und Schottland 1826/7 gesammelt hatten (Dietrich 1960: 255). Zugleich arbeitete Rose an den Katalogen der Mineralsammlung weiter und stellte im April 1826 den Katalog der großen systematischen Mineralsammlung fertig. Er erhielt bald danach, am 3. 6.1826, den Titel eines a. o. Professors, blieb aber weiterhin Gehilfe. Ein besonders ehrenvolles Ereignis für das Mineralogische Museum war dann die testamentarische Schenkung der Meteoritensammlung des am 3.4.1827 verstorbenen E. F. F. Chladni, des Begründers der Meteoritenkunde. Chladni erkannte damit die Förderung an, die die Meteoritenkunde und auch er persönlich durch Weiss und durch Rose erfahren hatten (Hoppe 1977, 1987b). ${ }^{36}$ Im Jahre 1829 entschloss sich die Berliner Gesellschaft naturforschender Freunde, ihre Sammlung an Mineralien allmählich aufzulösen, was sich über Jahre hinzog. Das Mineralogische Museum erwarb Teile davon, als Erstes im Jahre 18303 wertvolle Proben von Meteoriten (HHMfN-1, Band VIII).

Bedeutendes Material für die Mineralsammlung des Mineralogischen Museums stammt von der russischen Reise A. v. Humboldts im Jahre 1829. an der Rose als mineralogischer Reisebegleiter teilnahm ${ }^{37}$. Dank der großzügigen Unterstützung der russischen Regierung konnten umfangreiche Aufsammlungen, vor allem im Ural und Altai, gemacht werden. Hinzu kamen noch zahlreiche Geschenke, die A. v. Humboldt während und nach der Reise erhielt. Alles das bil-

\footnotetext{
${ }^{34}$ Das Zoologische Museum der Berliner Universität betrieb unter dem Direktor Professor H. Lichtenstein (1780-1857) einen vom Ministerium gebilligten Dublettenverkauf.

${ }_{35}$ Zur gleichen Zeit war auch Mitscherlich in Paris und London. wo Rose zeitweilig mit diesem zusammen wohnte. - Die Reise Mitscherlichs war durch Fürsprache A. v. Humboldts bei Minister v. Altenstein gefördert worden (Mitscherlich 1896 62).

36 Unter ande em hatte Weiss für die Ausgrabung einer großen vermeintlich meteorischen Eisenmasse in Aachen gesorgt und Rose bestimnte erstmals Minerale in Steinmeteoriten (Rose 1825)

37 $\mathrm{Zu}$ dieser Reise war v. Humboldt von der russischen Regierung in der Erwartung eingeladen worden, von ihm eine fundierte Beguta:htung der Edelmetallvorkommen des Urals zu erhalten. - Ein weiterer Reisebegleiter war C. G. Ehrenberg $(1795-1876)$.
} 
dete für Rose ein umfangreiches Arbeitsmaterial, das er in den nächsten Jahren intensiv untersucht hat, in erster Linie zunächst die Proben aus den vielen besuchten Gold- und Platingruben. Dies weitete er aber umfassend aus, so dass seine zahlreichen Veröffentlichungen und sein Reisewerk (Rose 1837/1842), in dem er die Ergebnisse zusammengefasst hat, eine neue Qualität der mineralogischen Kenntnis des besuchten Gebietes darstellten (Hoppe 2001).

In der Zeit, als Rose in Russland war, bot der Berliner Bankier F. Tamnau (1802-1879) den Verkauf eines Teils seiner großen Mineralsammlung an, der allerdings erst 12 Jahre später realisiert wurde. Diesem Verkaufsangebot, ebenso der Wiederholung von 1831 gegenüber verhielt sich Weiss trotz der deutlich gezeigten Aufgeschlossenheit des Ministers v. Altenstein sehr reserviert. Weiss nahm an, dass sich Tamnau nur von wenig wertvollen Stücken seiner Sammlung befreien wollte und hielt auch nach einer Besichtigung, die aber aus Platzmangel nicht vollständig möglich war, den angebotenen Teil nicht für das Mineralogische Museum geeignet. Tamnau betrieb aber seine Mineralliebhaberei auf hohem wissenschaftlichen Niveau und vervollständigte seine Sammlung ständig durch großzügige Käufe bei Mineralhändlern. Erst nach einem im Jahre 1840 durch ihn wiederholten Angebot, dem er ein gemeinschaftliches Gutachten' von Rose und Mitscherlich beigefügt hatte, kam der Kauf 1841 zustande. Es handelte sich um eine Mineralsammlung von 34000 Stück, deren Preis von 18000 Talern im Hinblick auf ihre Qualität als moderat eingeschätzt wurde. ${ }^{38}$

Nach der russischen Reise hoffte Rose, dass seine Stellung als Gehilfe am Mineralogischen Museum in eine höhere Position gehoben würde, zumal er schon vor Jahren im Protokoll einer ministeriellen Inventarüberprüfung als Inspektor der Sammlung bezeichnet worden war, und wandte sich am 22.3.1832 mit einem Antrag an den Minister. In einer Stellungnahme hierzu erklärte Weiss, er habe dieses Ansinnen schon vor zwei Jahren, als Rose es ihm nach der Rückkehr von der Russlandreise als Begleiter v. Humboldts vorgebracht hatte, als Anmaßung zurückgewiesen. Auch unterstellte Weiss, dass Rose ihn von seiner Position verdrängen wolle, was einen „offenen und unheilbaren Bruch" zur Folge habe. Es gelang dem Minister v. Altenstein jedoch, Weiss allmählich zum Einlenken zu bewegen (GSTAB-22, Bl. 27-123), und Rose erhielt eine höhere Besoldung als außerordentlicher Professor am Mineralogischen Museum.

Die Gehilfenstelle war nun frei und wurde am 24. 6. 1833 mit F. A. Quenstedt (1809-1889) besetzt, der seit 1830 Schüler von Weiss war und sich bereits im 4 . Studienjahr erfolgreich kristallographisch betätigte. Er konnte Weiss mit der Weiterentwicklung einer Projektionsmethode (Quenstedt 1835), überraschen“ (W. Quenstedt 1941). Ihm fiel nun unter anderem die Aufgabe $\mathrm{zu}$, die inzwischen sehr umfangreich gewordene Petrefaktensammlung des Mineralogischen $\mathrm{Mu}$ seums zu katalogisieren. $\mathrm{Zu}$ einem immer mehr steigenden Anteil bestanden die Erwerbungen des Mineralogischen Museums aus paläontologischen Sammlungsobjekten. So enthielt die im Jahre 1837 gekaufte Sammlung des verstorbenen Berliner Apothekers Bergemann entgegen dem publizierten Katalog auch zahlreiche Versteinerungen. Dieser Katalog war 3 Jahre zuvor durch einen Schüler von Weiss, E. Kayser, erarbeitet und publiziert worden (Kayser 1834) (39 $^{39}$ und erfasste nur die fast 12000 Minerale der Sammlung (GSTAB-20, B1. 7-12; GSTAB-23).

Besonders bemerkenswert ist, dass es sich A. v. Humboldt hat angelegen sein lassen, seinen Einfluss, den er als Kammerherr beim König hatte, für die Durchsetzung von Sammlungskäufen für das Mineralogische Museum zu nutzen (Hoppe \& Barthel 1986), mehrfach waren es paläontologische Sammlungskäufe. Dazu gehört der Ankauf der aus 400 fossilen Conchylien des Pariser Tertiärs bestehenden Sammlung Deshayes im Jahre 1832 (GSTAB-22, Bl. 22-23), die A. v. Humboldt in Paris vermittelt und auch den Kaufpreis von 1000 Franc ,aus eigenen Mitteln vorgeschossen" hatte. Ganz besonders wertvoll

\footnotetext{
38 GSTAB-21, Bl. 151-4, GSTAB-22, BI. 13-5 und GSTAB-20, B1. 18-35. -- Friedrich Tamnau war ein bedeutender Mäzen der Mineralogie (Groth 1954). Er hinterließ dem Mineralogischen Museum der Berliner Universität testamentarisch 12000 Taler zu einer Reisestiftung für mineralogische Sammelreisen (AHUB-2), deren Zinsen bis zur Geldentwertung durch die Inflation etliche Male genutzt wurden, ferner hinterließ er dem Gewerbe-Institut, d. h. der Technischen Hochschule Berlin-Charlottenburg, eine Mineralsammlung von 50000 Stück. Diese ging 1938 nach Darmstadt, wo sie 1967 im Mineralogischen Institut der Universität aufgestellt wurde (Paulitsch 1970). Schließlich erbte der Enkel A. v. Janson weitere Mineralbestände. die 1899 vom Mineralogischen Museum der Berliner Universität gekauft wurden.

${ }^{39}$ Die Publikation des Kataloges hatte deren Verfasser E. Kayser im Jahre 1834 dazu benutzt, einen Antrag auf Anstellung als Gehilfe am Mineralogischen Museum zu stellen. In seinem Gutachten empfahl Weiss ihn für eine anderweitige Anstellung und erklärte Quenstedt für Berlin als geeigneter (GSTAB-25, Bl. 16-20).
} 
war aber die 1833 erworbene umfassende paläontologische Sammlung des Gothaischen Oberhofmarschalls E. F. Frhr. v. Schlotheim (1764-1832). In ihr sind die Originale enthalten. anhand denen Schlotheim zahlreiche Arten aufgestellt und beschrieben hat (Schlotheim 1820). Es sind vorwie send Versteinerungen von Tieren. aber bereits alch von Pflanzen. was ihn zu eincm der Begründer der Paläobotanik gemacht hat. Für diese 1 Ankauf hatten sich auch L. V. Buch und besonders eindringlich A. v. Humboldt eingesetzt (GS'TAB 24. Bl. 1-150), auch Dietrich 1960: 258), wobei Letzterer u. a. auf ..die Armuth unserer Sammlungen an Petrefakten" hingewiesen hatte (Schuster 1922: 108). Ferner sind die Bemühungen von Weiss in den Jahren 1835 und $1836 \mathrm{zu}$ erwähnen. wodurch die Erwerbungen von Fähitenplatten des Chirotheriensandsteins aus der Gegend von Hildburghausen möglich wurden."

Im Verlauf der Katalogarbeiten. besonders anhand der Schlotheim-Sammlung. gelang es Quenstedt. sich umlangreiche paläontologische Kenntnisse zu erwerben. und er konnte 1836 mit einer Dissertation über die Merkmale der Nautiliden promovieren (Quenstedt 1836). Der Katalog der Petrefaktensainmlung wurde 1837 fertig (GSTAB-25. B31. 84-86). ${ }^{\text {t1 }}$ Aus dem ..QuenstedtKatalog*. der noch heute genutzt wird. geht hervor, dass die paläontologische Sammlung des Mineralogischen Museums mit bereits 15980 Nummern paläozoologischer und 1882 Nummern paläobotanischer Objekte einen bedeutenden Umfang hatte (Köpke 1860: 280). Quenstedt wurde an die Unversität Tübingen berufen und verließ 1837 Ber in. Sein Nachfolger als Gehilfe am Mineralogischen Museum wurde H. F. Emmrich (1815-1879) (GSTAB 25, Bl. 79-83), der seit 1835 Schüler von Weiss war. Er promovierte mit einer paläontologischen Dissertation über Trilobite (Emmrich 1839). blieb aber aus familiären Gründen nur bis zum Frühjahr 1839 und ging dann in seine Heimatstadt Meiningen in den Schuldienst (Böhme 1967). Sein Nachfolger als Gehilfe wurde H. Girard (GSTAB-25. B1. 152), ebenfalls ein Schüler von Weiss. der 1840 mit einer Dissertation über Basalte promovierte (Girard 1840) und später als Privatdozent auftrat.
Im Jahr 1839 gab es am 27. Mai einen Museumsdiebstahl, bei dem Edelmetallstufen und Edelsteine im Wert von 2000 Taler gestohlen wurden (GSTAB-27: Hoppe 1983). Es war eine gezielte Aktion einer Diebesbande, bei der der 1837 eingetretene Aufwärter Reichel ${ }^{42}$ überlistet worden war. Die Bande konnte gefasst und das Diebesgut teilweise wiedererlangt werden, wobei sich der vorhandene Katalog als schr günstig erwies. konnte doch Weiss genau angeben, welche Gegenstände gestohlen waren. Reichel wurde entlassen. obwohl ihm keine Mitwirkung nachgewiesen werden konnte. Als nächster Aufwärter wurde dann der ehemalige Unteroffizier Fischer eingestellt.

Die Lehrtätigkeit am Mineralogischen $\mathrm{Mu}-$ seum im Zeitraum 1820-1840 war komplexer als im ersten Jahrzehnt. C. S. Weiss, nun am Höhepunkt seiner Laufbahn, setzte zunächst seine Vorlesungen in der gleichen Weise fort. wie er sie zuvor entwickelt hatte. Er hielt einen sechsstündigen Grundkurs Mineralogie, der auch Geognosie mit umfasste und sich über zwei Semester erstreckte, und dazu noch besondere Vorlesungen über Geognosie und über Kristallographic. Letztere mit variierenden Titeln und Inhalten, vorwiegend mathematische Kristallographie und Kristallonomie, auch beschreibende Kristallographie. Nach wenigen Jahren zeigten sich verschiedene Abweichungen von diesem Lchrprogramm. Damit ist nicht nur die zusätzlich von ihm gehaltene Vorlesung über Bodenkunde für Forstleute von 1822 bis 1830 gemeint, sondern das öftere Verkürzen seiner Vorlesung über Mineralogie seit 1825 und mehrfaches Weglassen seiner Vorlesungen zu kristallographischen Themen, die er auch nur noch Kristallographie nannte. Ferner fällt auf, dass Weiss von 1832 bis 1836 in fast jedem Semester mineralogische Übungen ankündigte, die er nur in den ersten Jahren der Universität einige Male genannt hatte. Im Jahre $1835 \mathrm{kam}$ es schließlich zu einer nachhaltigen Einschränkung seines Lehrprogrammes, da er von nun an (mit Ausnahme von 1838) seine vertiefte Geognosievorlesung nicht mchr las. Diese Vorlesung hatte er ganz im Sinne Werners gelesen, wie eine Nachschrift seines Schülers H. v. Dechen aus dem Jahre 1819

\footnotetext{
"II Herm Dr. э. Böhme wird für detaillierte Mitteilungen dazu gedankt. - Weitere paläontologische Sammlungserwerbungen sind bei Köfke (1860): 280) und Dietrich (1960: 255) aufgeführt.

41 Quenstedt :rhielt für die Herstellung des Kataloges eine Gratifikation von 100 Taler. sein Helfer Emmrich 30 Taler.

tz Der langiäl rige Aufwärter Hellwig war 1837 gestorben. - Hellwigs Wilwe richtete wegen ärztlich bestätigter völliger Arbeitsunfähigkicit cine Bitschrift um eine Rente an das Vinisterium, die aber als nicht möglich abgelehnt wurde. Viele Jahre lang erhielt sie jahrlich aul Bittschreiben sine Unterstüzung in Höhe von je 15 oder 10 Taler (GSTAB-25 und 26).
} 


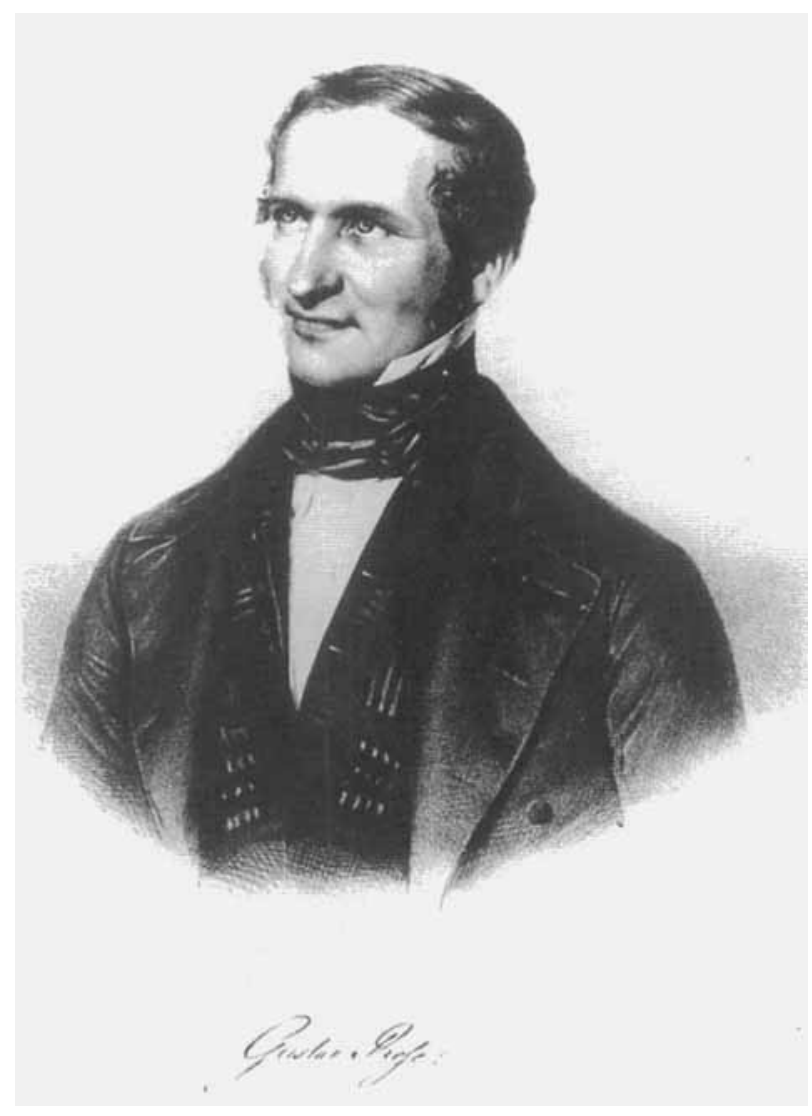

Abb. 4. Gustav Rose (1798-1873), Porträt, etwa zur Zeit der russischen Reise; Lithographie von Rohrbach nach einer Zeichnung von Paul Bürde. - Original im Mineralogischen Institut der Humboldt-Universität Berlin.

Fig. 4. Gustav Rose (1798-1873) at the time of his Russian travel; lithograph by Rohrbach after a drawing of Paul Bürde. - Original in the department of mineralogy of the Humboldt University Berlin.

deutlich zeigte, ${ }^{43}$ und konnte sich zunächst nicht von den inzwischen überholten Ansichten lösen. Dies musste aber eintreten, als Weiss die von dem sächsischen Offizier C. A. v. Gutbier im Elbtal festgestellten Überschiebungen von Granit auf Sedimente aufgriff (Weiss 1827), die der Lehre Werners entgegenstanden. Eine andere Vorlesungsnachschrift von $1833^{44}$ lässt erkennen, dass Weiss zwar in der Lage war, die Geologie Werners einer Kritik zu unterziehen, aber nicht, um eine eigenständige Vorlesung über dieses Gebiet zu entwickeln.
Die Veränderungen der Vorlesungen von Weiss sind wohl auch Reaktionen darauf, dass er seit 1825 nicht mehr der alleinige Lehrer der Mineralogie war. Schon im Jahre 1820 hatte sich mit der Promotion von Gustav Rose (Abb. 4) das Heranwachsen des Nachwuchses von Lehrkräften in der Mineralogie angebahnt. Es dauerte allerdings noch bis 1825 , bis Rose mit einer vierstündigen Vorlesung über Mineralogie auftrat. Von 1828 an las er im Sommer- und Wintersemester abwechselnd über Mineralogie und „Über die Anwendung der Mineralien in der Technologie und Pharmazie". Letztere Vorlesung ließ er von $1833 \mathrm{ab}$ fallen und las von da an über die mineralogische Beschaffenheit der Gesteine, was er bald danach Petrographie und ab 1837 Geognosie nannte.

Im Jahre 1833 kam der sehr befähigte Geologe Friedrich Hoffmann ${ }^{45}$ als a. o. Professor nach Berlin. Er war zuvor Privatdozent bzw. a. o. Professsor an der Universität Halle und konnte von Herbst 1829 bis Früjahr 1833, empfohlen von L. v. Buch und A. v. Humboldt sowie gefördert durch Minister v. Altenstein, geologische Studien in Italien und Sizilien betreiben. Danach wechselte er nach Berlin und hielt Vorlesungen über allgemeine Geognosie, physikalische Geographic. Erdbeben und Vulkane sowie auch über Versteinerungskunde, jedoch nur 4 Semester lang, da ihn eine schwere Krankheit ereilte, die auch eine vorgesehene Harzexkursion mit Studenten unmöglich machte. Noch nicht 39 Jahre alt, verstarb er am 6.2.1836 (Hoffmann 1837: XII-XXIV).

Ein weiterer Vortragender war der schon genannte F. A. Quenstedt, der im Vorlesungsverzeichnis des Sommersemesters 1837 mit den Vorlesungen „Allgemeine Versteinerungskunde“ und "Geologische Untersuchungen über den Erdkörper und seine vorweltlichen Geschöpfe"* sowie „Petrefactologische Übungen“ auftrat. Da er bereits zu Michaelis 1837 ausschied, um nach Tübingen zu gehen, blieb es bei diesem einen Semester Vorlesungen.

\footnotetext{
43 Dieses Kollegheft gelangte in das Geologenarchiv des Berliner Geologen E. Haarmann, der es im Rahmen einer ausführlichen Vorstellung seines (bald darauf durch Brand zerstörten) Archivs auswertete (Haarmann 1942: 168-171). Haarmann glaubte erwarten zu können, dass Weiss in seiner Geognosievorlesung bereits als Überwinder von Werner auftrat, und leitcte aus dem Kollegheft von 1819 über Weiss das Urteil ab: „Aber als Geologe bedeutete Weiss nichts. [...] Werners Lehre vermachte er unkritisch der damaligen Jugend". Ungeachtet der wohl übertriebenen Schärfe der Bewertung wird aber dadurch bestätigt, dass sich Weiss von Werner noch nicht lösen konnte.

44 Das von $H$. Bcyrich stammende Kollegheft (HHMfN-6) zeigt, dass Weiss die Lehre Werners vortrug und dabei nicht müde wurde, zugleich auf die Fehler Werners ausführlich hinzuweisen (Hoppe 1982: 249).

${ }^{45}$ Hoffmann hatte Medizin zu studieren begonnen, war aber zur Mineralogic übergegangen, als er in Göttingen die Vorlesungen des Mineralogen und Geologen J. F. L. Hausmann hörte, und wurde dann in Berlin auch Schüler von Weiss. Er wandte sich danach geologischen Arbeiten zu, vorwiegend über Nordwestdeutschland. - Sein Vater, J. G. Hoffmann (1765-1847), war ord. Professor der Staatswissenschaften an der Universität Berlin.
} 
Es ist auch zu erwähnen, dass in den Jahren von 1835 bis 1341 an der Universität bergbaukundliche Vorlesungen liefen. die die Bergverwaltung sonst ohne Universitätsbeteiligung veranstaltete. Sie wurden von dem Geheimen Oberbergrat H v. Dechen (1800-1877), einem früheren Schülır von Weiss, gehalten, der von Bonn aus für e nige Jahre an das Ministerium in Berlin versetzt worden war. Er las als a. o. Professor im Rahmen der Staats-. Kameral- und Gewerbewissenschaften über Bergbaukunst. über den Gebrauch der Dampfmaschinen beim Bergbau und auch über Markscheidekunst. Für die Geowissenscha ten war es bedeutender. dass er daneben auch Vorlesungen über die Grundsätze der Geognosie. auch einmal über die geognostische Beschaffenheit Norddeutschlands ankündigte. Die Vorlesungstätigkeit v. Dechens in Berlin endete, als er 1841. nun als Berghauptmann. wieder nach Bonn zurückging.

Betrachtet man als Nächstes die wissenschaftliche Publikationstätigkeit von Weiss. so zeigt sich in der Periode $1820-1840$ eine Veränderung. War sie zuvor durch wesentliche Beiträge zu den Grundlagen der Kristallographie gekennzeichnet. so verlagerte sie sich nun auf verschiedene Teilfragen der Kristallographie. wie die Ableitung bestimmter Kristallgestalten mithilfe der von ihm stammenden Flächensymbole (Weiss 1822a, 1825) sowie auf die Bearbeitung der Kristallographie einiger Minerale, wie zum Beispiel Gips (Weiss 1822b) oder Staurolith (Weiss 1832). ${ }^{\text {th }}$ Weiss machte auch den Versuch, die mit seiner naturphilosophischen Einstellung gewonnene Bewertung der Kristallachsen als bevorzugte Kraftrichtungen zu einer Kohisionstheorie zu erweitern (Weiss 1834), was er aber nicht zu Ende führte.

Außer Weilis traten allmählich auch andere deutsche Miniralogen auf, die sich kristallographisch betätigten. $\mathrm{Zu}$ diesen gehörte der schon genannte Schüler von Weiss. F. E. Neumann. der besonders an allgemeinen Problemen der Kristallographie interessiert war und zunächst mit mathematischen Weiterentwicklungen und Projektionsverfahren auftrat (Neumann 1823, 1826). aber nach seiner Berufung nach Königsberg allmählich zur Fhysik überging. Auch von anderen
Seiten gab es Entwicklungen in der Kristallographie, so von F. Mohs (1773-1839), dem Nachfolger von Werner in Freiberg, der mit einer Kristallsystematik auftrat (Mohs 1822), in der er schiefwinklige Achsen zuließ, ansonsten jedoch die Systematik von Weiss verwandte, aber unter Vermeidung von dessen Benennungen. Weiss geriet mit Mohs in Streitigkeiten, als er dessen Mineralsystem, das allein auf mineralogischer Basis ohne chemische Kriterien beruhen sollte, und dessen (wie in der Zoologie übliche) binäre Nomenklatur kritisierte (Weiss 1829), was eine höchst heftige Auseinandersetzung zwischen Mohs und Weiss zur Folge hatte (Mohs 1829/30, Weiss 1830). Bedeutender als Mohs war dessen Schüler C. F. Naumann (1797-1873), der von Mohs die Schiefwinkligkeit der Achsen bei niedrigsymmetrischen Kristallen übernahm und von 1825 an Lehrbücher der Kristallographie (u. a. Naumann 1830), Mineralogie und Geologie schrieb, aber mit Weiss nicht in Kontroversen kam. Seine Art der Benennung der Kristallflächen und der Kristallsysteme war durch Einbeziehung der Kristallsymmetrie mnemotechnisch günstiger als die von Weiss, sodass sie lange Zeit vielfach bevorzugt wurde. ${ }^{47}$ Besonders Naumanns Lehrbuch der Mineralogie (Naumann 1828) war sehr wirksam und ist in zahlreichen Auflagen erschienen.

Allmählich verlor Weiss die Führung in der weiteren Entwicklung der Kristallographie. Teile der Ansichten von Weiss stellten sich inzwischen als unzutreffend heraus. Vor allem traf es nicht zu. dass die genauere Messung der Kristallwinkel ersetzt werden kann durch Berechnungen auf der Basis von Quadratwurzelverhältnissen niedriger ganzer Zahlen, da dies nur für reguläre Kristalle exakt ist. Auch seine Versuche, in allen Fällen mit rechtwinkligem (bzw. hexagonalem) Achsenkreuz auszukommen, um schiefwinklige Koordinaten zu vermeiden, bewährten sich nicht. Ferner erwies sich die optische Methode der Winkelmessung mithilfe des Reflexionsgoniometers als unumgänglich, da sie bei der Messung von Flächenwinkel die höchste Genauigkeit erzielen kann. Auch war es damals nicht berechtigt. Mitscherlichs Feststellungen der Gleichheit

\footnotetext{
th Weitere Pu likationen sind in Poggendorffs Biografisch-literarischem Handwörterbuch verzeichnet. - In diese Richtung reihte sich auch die Dissertation von Rose (1820) ein. die das Mineral Titanit betraf und in der sich Rose zunächs noch ganz als Schüler von Weiss zeigte, indem er den ..Verbesserungen“ folgte. die Weiss an den gemessenen Kristallwinkeln durch vermsintlich bessere trigonometrische, auf den Quadratwurzelverhältnissen niedriger Zahlen beruhende Ansälzo vornahm.

${ }^{7}$ Durch den späteren Nachweis der Kristallgitternatur erwies sich das auf Weiss und Miller beruhende Verfahren den Naumannschen Symbolen überlegen.
} 
der Kristallwinkel bestimmter Kristallarten (Mitscherlich 1820) für irrig zu erklären, wie Weiss es tat, und schließlich durfte die Entdeckung Mitscherlichs, dass bei Temperaturveränderungen messbare Veränderung der Kristallwinkel an Gipskristallen, d. h. bei einem nicht regulär kristallisierendem Mineral, auftreten (Mitscherlich 1837), nicht mehr als Messfehler abgetan werden.

Der Charakter von Weiss bewirkte es, dass er eigene Fehler und Schwächen nur schwer erkannte. Dies führte zu Aversionen und Handlungen, die den Lehr- und Forschungsbetrieb ungünstig beeinflussten. Besonders das Verhältnis von Weiss zu Rose war bereits frühzeitig sehr gespannt. Auslöser war die enge Verbindung Roses mit Mitscherlich, die sich schon bei Mitscherlichs Isomorphieentdeckung gezeigt hatte und die weiter bestehen blieb, da Rose das Reflexionsgoniometer Mitscherlichs für eigene Zwecke benutzen konnte. Es ging so weit, dass Weiss versuchte, Rose vom Mineralogischen Museum zu verdrängen. ${ }^{48}$ Auch der Geologe F. Hoffmann bekam die Haltung von Weiss zu spüren, da Weiss ihm die Benutzung der Sammlungen für die Vorlesungen, die dieser seit 1833 hielt, nur unter seiner Kontrolle gewähren wollte. Hoffmann konnte sich gegen Weiss nicht durchsetzen und bat im März 1834 den Minister v. Altenstein, persönlich einzugreifen (GStAB-22, B1. 153-63, 177--84). Dennoch war Weiss nicht $\mathrm{zu}$ bewegen, Hoffmann uneingeschränkten $\mathrm{Zu}$ gang zu gewähren.

Auch die Studenten bekamen die Beschränkungen der Sammlungsnutzung zu spüren. Der Chemiker und Mineraloge K. F. Rammelsberg drückte später seine Erinnerung daran in freundlichen Worten so aus (Rammelsberg 1880): „Wenn nach dem Schluss der Vorlesung einige Lehrbegierige ihn umstanden, dann war er unermüdlich im Demonstrieren, dann war er sogar in der Stimmung, uns zu gestatten, dass wir ein Stück der Sammlung in die Hand nehmen durften".

Aber auch Weiss selbst empfand die Situation, die sich eingestellt hatte, als Belastung. Man erfährt dies aus Bemerkungen, die er gegen seinen früheren Schüler F. Neumann äußerte, als dieser ihn am 30. Juni 1834 von Königsberg aus besuchte. Darüber schrieb Neumann seiner Frau
(L. Neumann 1904, S. 300): „Eben komme ich von Weiss zurück. [...] Weiss ist sehr trübe gestimmt, wegen vieler unangenehmer Verhältnisse; das geht so weit, dass er sich bedenkt, ob er seine Stelle niederlegen soll oder sich beim Könige beschweren".

Tatsächlich kam es am 24.7.1834 zu einer Beschwerde von Weiss bei Minister v. Altenstein, vorgebracht innerhalb einer 26 Seiten starken Eingabe, in der er sich ausführlichst zu den Forderungen von Hoffmann äußerte und in der er seine Haltung hierzu und zu den mehrfach erhaltenen Anweisungen des Ministeriums begründete (GStAB-25, Bl. 3-15). Neben den Problemen der Beschaffenheit und Unterbringung der Sammlung brachte Weiss auch die Tätigkeit von Rose im Mineralogischen Museum zur Sprache, die für ihn ein Problem darstellt, da Rose ihm die Hörer entzichen und seine Stellung sowie seine Befugnisse beeinträchtigen würde. Weiss äußerte dabei auch die Vermutung, dass möglicherweise die früheren Verordnungen zur Katalogisierung, Ordnung und öffentliche Benutzung der Sammlung dazu gedient haben könnten, ihn zur Niederlegung seiner Stelle zu bewegen, und ersuchte den Minister um „eine einfache und unumwundene Erklärung" in dieser Hinsicht.

Rose dagegen glaubte den Schwierigkeiten mit Weiss dadurch zu entkommen, dass er eine etwas andere Richtung einschlagen müsste, und beabsichtigte eine Vorlesung über die technische Anwendung der Minerale zu halten. Dies erschien ihm nach dem am 22.10. 1833 eingetretenen Tode seines Onkels, des Professors der technischen Chemie an der Berliner Universität S. F. Hermbstaedt (1760-1833), möglich und er erbat die hierfür notwendigen Mittel bei dem Minister. Jedoch ging der Minister v. Altenstein aufgrund eines Gutachtens Mitscherlichs hierauf nicht ein. Dieser hatte dafür plädiert (GSTAB-22, Bl. 146--9), dass Rose bei seiner Richtung bleiben solle, da er das von Rose Beabsichtigte in seinen Vorlesungen selbst behandelt, und machte den Vorschlag, dass Rose seine bisherigen Vorlesungen auf den Zusammenhang zwischen der Form und der chemischen Zusammensetzung der Minerale erweitern solle, wofür allerdings auch Mittel des Ministers notwendig wären. ${ }^{49}$

\footnotetext{
48 Das Vorgehen von Weiss charakterisierte Mitscherlich in einem Brief an Berzelius am 18. 12.1832 mit den Worten: Weiss benütze ,.die Zeit, in welcher er Rektor der Universität ist [d. h. 1832/33], um Gustav Rose ganz vom mineralogischen Kabinett zu entfernen". (Mitscherlich 1896: 104).

${ }_{49}$ Im Jahre 1834 wurde die Position Roses dadurch gestärkt, dass er auf Vorschlag von A. v. Humboldt als Mitglied in die Berliner Akademie der Wissenschaften aufgenommen wurde (ABBA-15).
} 
Der Groll von Weiss gegen Rose schwelte noch lange Zet weiter. Zur Unterstützung für seine Mineralog̣ievorlesung hatte Rose als erstes Kapitel seines beabsichtigten Lehrbuchs der Mineralogie eine kurzgefasste Übersicht über die Kristallographiє: herausgebracht (Rose 1833). für die sich 1838 eine zweite Auflage nötig machte. Hinweise auf cie Kristalltheorie von Weiss enthielt das Buch richt und beschränkte sich auf die praktische Anwendung in der Mineralogie. Weiss sah dies anders. In einem Brief an seinen Freund, den dänischen Physiker H. C. Örsted (1777-1851) vom 5. 8. 1838 (Örsted 1920. S. 346) äußerte er sich dazu und zu der von ihm empfundenen Isolierung in Berlin. Indem er Horaz zitierte: „Tantum de medio sumptis accedit honoris!"*5"), schrieb ər weiter:

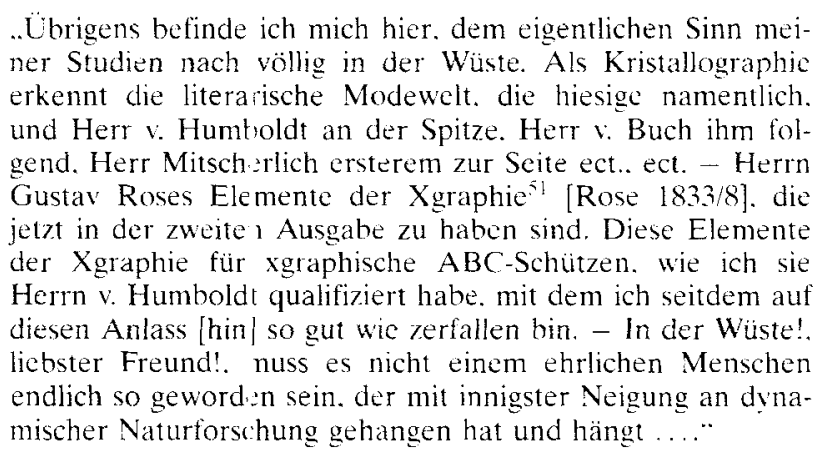

Danach scheinen aber doch ruhigere Zeiten im Mineralogisch $€ n$ Museum eingezogen sein, denn Rose durfte sich offenbar mit Billigung von Weiss wegen der Genehmigung der Anschaffung eines Mikroskopes am 21.5. 1838 an den Minister wenden (GSTAB-25. Bl. 118-9). Rose verweist in dem Antrag zu nächst auf die erfolgreichen mikroskopischen Studien von Ehrenberg an staubfeinen Substanzen und auch auf seine eigenen. mithilfe des Mikroskops Ehrenbergs erreichten und bereits publizierten Ergebnisse an mikrokristallinen Niederschlägen (Rose 1837a). Weiter heißt es dort: Schon vor mehreren Jahren hat Herr Professor Weiss, die Nothwendigkeit eines Laboratoriums bei der Königlichen Mineraliensammlung wohl einseherd. mir dazu auf meine Bitte zwei Zimmer in den Entresols [Zwischengeschossräumen] über de - Mineraliensammlung eingeräumt. in welchen ich jedoch alle Einrichtungen ganz auf meine Kosten gemacht habe". Rose bittet nun wegen der Kosten, die ihm der Betrieb des Labora- toriums auch weiterhin macht, da er selbst für die Reagentien und dergleichen aufkommen muss, die Anschaffung eines Mikroskop zu genehmigen und die Kosten zu übernehmen.

Schließlich kam es zur endgültigen Festigung von Roses Stellung in Berlin, da er am 17.3. 1839 den Titel eines ordentlichen Professors der Mineralogie erhielt. Das Mineralogische Museum hatte damit zwei ordentliche Professoren, wobei Weiss der Direktor des Mineralogischen Museums blieb.

\section{Die Zeit von 1840 bis 1856 - \\ C. S. Weiss, G. Rose und E. Beyrich}

An den Beginn dieses Abschnittes wird eine Eingabe von Weiss an das Ministerium vom 12. 11.1840 (GSTAB 25, B1. 173-4) gestellt, in der er darauf hinwies, dass es notwendig wäre, Vorlesungen über Versteinerungskunde, das „Fundament der neueren Geognosie", zu halten, wie sie bereits durch Quenstedt begonnen worden waren, und empfahl hierfür seinen nunmehr zur Verfügung stehenden Schüler Beyrich als Dozenten.

Heinrich Ernst Beyrichs (Abb. 5) akademischer Werdegang (Hauchecorne 1897, Helms 1997) hatte schon 1831 mit 16 Jahren begonnen, als er sich in Berlin immatrikulieren ließ und sich danach unter Weiss bevorzugt der Geologie zuwandte. Er war dann 1834 nach Bonn gegangen. um sich bei dem Professor für Zoologie und Mineralogie G. A. Goldfuss (1782-1848) und dem Professor für Mineralogie und Bergwerkswissenschaft J. Nöggerath (1788-1877) zoologisch-paläontologisch $\mathrm{zu}$ vervollkommnen, und war dann nach zweijährigen Geländestudien im Rheinland 1837 wieder nach Berlin gekommen, wo er mit einer Dissertation über Goniatiten des Rheinischen Schiefergebirges (Beyrich 1837) promovierte. Anschließend war er auf eine groBe Studienreise in die Schweiz, Frankreich und Norditalien gegangen.

Nach seiner Rückkehr stellte Weiss den eben genannten Antrag. Minister Eichhorn ${ }^{52}$ erklärte sich einverstanden, dass über das neue Fach Versteinerungskunde Vorlesungen gehalten werden und hierfür eine Lehrstelle eingerichtet wird, machte aber deren Realisierung von der Geneh-

\footnotetext{
51) Der Ausspruch von Horaz bedeutet ctwa: ..So viel Ehre für Mittelmäßiges!"

5 Als Abkürzıng für Kristall wird hier der Buchstabe X verwendel.

52 Nach dem Jod des Ministers $x$. Altenstein am 14.5. 1840 übernahm J. A. F. Eichhorn (1779-1856) im August 1840 das Amt als preußisc rer Kultusminister. - In diesem Jahr starb auch Friedrich Wilhelm III. am 7.6.1840 und Friedrich Wilhelm IV. $(1795-1861)$ vurde preußischer König.
} 


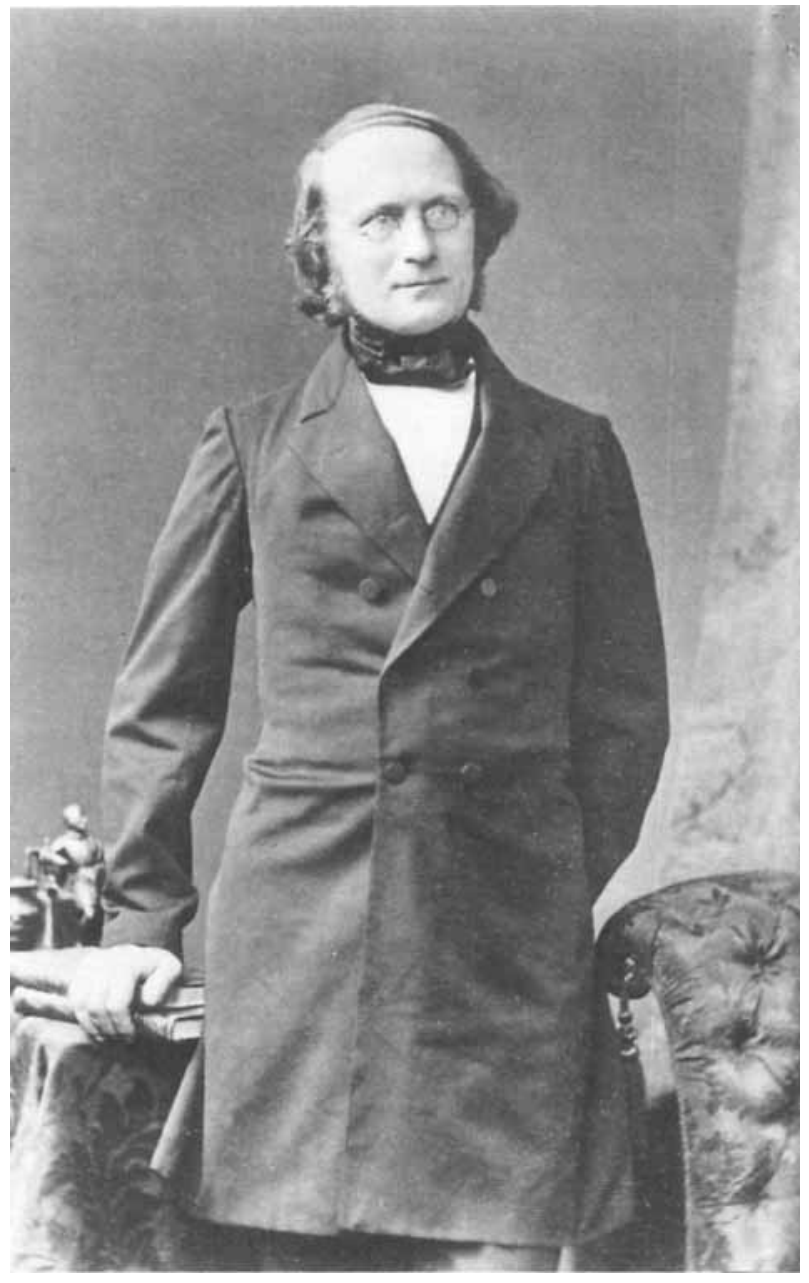

Abb. 5. Ernst Beyrich (1815-1896), fotografisches Porträt. Original im Paläontologischen Institut der Humboldt-Universitiat Berlin.

Fig. 5. Ernst Beyrich (1815-1896), fotografy. - Original in the department of paleontology of the Humboldt University Berlin.

migung der Fonds durch den König abhängig (GSTAB-25, Bl. 176). Dies zog sich noch hin und Beyrich konnte schließlich am 18.5.1841 als Privatdozent tätig werden (Asen 1955: 15).

Am Ende des Jahres 1841 kündigte der Minister eine Erhöhung des Etats für das Mineralogische Museum, der bisher 1520 Taler betrug, um 1200 Taler an (GSTAB 25, Bl. 222), zu der Weiss einen Vorschlag der Aufteilung einreichen musste. Dieser Etatsentwurf (GSTAB-26, BI. 3-5) sah Folgendes an Gehältern vor: für den Professor G. Rose 400 Taler nebst 200 Taler Mietsent- schädigung, für den (mineralogischen) Gehilfen H. Girard 200 Taler, für den Aufwärter Fischer 200 Taler und für einen noch nicht benannten Gehilfen bei der „petrefaktologischen" Sammlung 120 Taler, ferner an sachlichen Ausgaben der Mineralsammlung 1200 Taler und der "petrefaktologischen" Sammlung 400 Taler. $^{53}$ Nach diesem Etatsentwurf konnte dann verfahren werden.

Die erste Vorlesung, die Beyrich hielt. fand im Wintersemester 1841/42 vierstündig statt und war angekündigt als: „Allgemeine Versteinerungskunde, erläutert durch Demonstrationen im Königl. mineralogischen Museum". Beyrich wechselte sie späterhin regelmäßig mit einer Vorlesung „Geognosie mit besonderer Rücksicht auf Versteinerungen" ab, las aber mehrfach an deren Stelle auch eine speziellere Vorlesung, die sich auf bestimmte Fossilgruppen bezog oder regional begrenzt war, u. a. auf Schlesien, den Harz oder die Berliner Gegend. Diese Lehrtätigkeit Beyrichs fand mit seiner Ernennung zum außerordentlichen Professor am 26.7.1846 Anerkennung.

Beyrichs Vorlesungen bildeten die geologischpaläontologische Ergänzung zu den Vorlesungen der Professoren Weiss und Rose. Weiss las über Mineralogie sechsstündig, mehrmals zusätzlich auch eine verkürzte Fassung, und über Kristallographie vierstündig, einige Male in ,beschreibende" und „rechnende“ Kristallographie aufgeteilt. Rose las eine fünfstündige Mineralogievorlesung und vierstündig über Geognosie (Grund- und vulkanisches Gebirge). In den letzten Lebensjahren kündigte Weiss keine Vorlesung über Kristallographie mehr an, die dann von Rose, allerdings nur einstündig, übernommen wurde.

Für die Bergeleven, oder wie sie auch genannt wurden, Bergwerks- und Hüttenbeflissene, war weiterhin die Teilnahme an der Mineralogievorlesung von Weiss vorgesehen. Für Letztere wurden außerdem Vorlesungen über Metallurgie und Hüttenkunde gehalten, die der Privatdozent der Chemie am Gewerbeinstitut und an der Universität K. F. Rammelsberg (1813-1899), ein mineralogisch und technisch orientierter Chemiker. seit 1843 hielt. $^{54}$ Rammelsberg bot bald auch

\footnotetext{
53 Das Gehalt für o. Prof. Wciss von 500 Taler (weitere 1200 Taler bezog Weiss von der Bergelevenkasse) wurde aus anderen Fonds gezahlt. - Das Gehalt von o. Prof. G. Rose war noch das Gleiche, wie er es als a. o. Professor bezogen hatte. auch die Mietsentschädigung erhielt er bereits seit 1827. E. Beyrich erhielt schließlich die 120 Taler jährlich.

54 Rammelsberg richtete 1846 im Auftrage der Bergbehörde ein Laboratorium für metallurgische Chemie und Hüttenkunde am Gewerbeinstitut Berlin ein (Strunz 1970: 18) und setzte seine Vorlesungstätigkeit im Rahmen der Universität für Bergelcven auch späterhin regelmäßig fort. Er wurde 1848 a. o. Professor und 1874 o. Professor der Mineralogie und Chemie an der Universität Berlin.
} 
Lehrveranstaltungen für Geowissenschaftler an, einige Male Lötrohrprobierkunde und seit 1849 fortlaufend die Vorlesung „Über die Anwendung der Chemie auf die Geologie” bzw. „Die chemischen Grundlehren der Geologie".

Das von den zuvor genannten Lehrkräften bestrittene Programm wurde in der Zeit von 1843 bis 1853 durch Vorlesungen mehrerer weiterer Vortragender ergänzt. Als Erster und zugleich am längsten trat T. E. Gumprecht (1801-1856) als Privatdozent mit geologischen und geographischen Vorlesungen auf. Er war ursprünglich Weinhändler in Posen gewesen, hatte dann an der Universität in Berlin, u. a. bei Weiss studiert. Seine Vorlesungen, die er von 1843 bis 1853 hielt, hatten die Themen: „Allgemeine Geognosie" und „Über die Charaktere der den Gebirgsformationen eigenthümlichen Versteinerungen", daneben auch "Geognostische Geographie von Deutschland".5." Gesundheitliche Probleme zwangen ihn, die Vorlesungen aufzugeben. Von 1845 bis 1849 trat auch ein jüngerer Schüler von Weiss mit Vor esungen auf. Es war der bereits als Gehilfe erwähnte H. Girard (1814-1878). Er las als Privatdozent Vorlesungen über Allgemeine Geognosie und Geognosie Norddeutschlands, auch über Vulkane und Erdbeben. Im Herbst 1849 ging er als Professor der Mineralogie und Geolog̣ie nach Marburg und später nach Halle. Sein Na:hfolger als Gehilfe am Mineralogischen Museum wurde Daniel Krull. der schon seit $1844 \mathrm{zu}$ Hilfsarbeiten herangezogen worden war (GSTAB-26, Bl. 224 und 282).

Interessanterweise findet man in den Vorlesungsverzeichnissen dieser Jahre einstündige Vorlesungen von drei Professoren verwandter Gebiete der Berliner Universität, die jeweils nur über ein Semester liefen und mit denen sich die Vortragenden offenbar den Mineralogen und Geologen vorstellen wollten. Es waren im Jahre 1845 der Cheniker E. Mitscherlich (1794-1863) mit der Vorlesung ..Über die chemische Zusammensetzung und Veränderung der Erdoberfläche", in den Jahren 1846 und 1847 der Anatom und Physiologe Johannes Müller (1801-1858) ${ }^{56}$ mit den Vorlesungen „Über fossile Fische und Reptilien“ bzw. „Über die fossilen Reste der Reptilien" und im Jahre 1851 der gerade nach
Berlin berufene Botaniker Alexander Braun (1805-1877) mit der Vorlesung „Über die Flora der Vorwelt". Mit dem Jahre 1854 hörten alle zusätzlichen Lehrveranstaltungen auf und nur noch Weiss, Rose, Beyrich und Rammelsberg kündigten Vorlesungen an.

Die Entwicklung der Sammlungen des Mineralogischen Museums im Zeitabschnitt ab 1840 ist durch bedeutende Erwerbungen gekennzeichnet. Im Jahre 1841 wurde der Ankauf der sehr bedeutenden Mineralsammlung Tamnau realisiert, der bereits im vorigen Zeitabschnitt näher dargestellt wurde. Im gleichen Jahr konnte der bei Grüneberg in Schlesien gefallene Meteorit durch das Mineralogische Museum gekauft werden. Um diesen Kauf kam es zu einem Streit mit dem Professor der Mineralogie an der Universität Breslau, E. F. Glocker, der vergeblich versuchte, die Zulässigkeit des Kaufs durch eine nicht in Schlesien befindliche Institution infrage zu stellen (GSTAB-25, Bl. 186-220).

Wie schon im vorigen Zeitabschnitt trat wiederum A. v. Humboldt als Vermittler und Beförderer für Erwerbungen auf, besonders für die paläontologische Sammlung. Speziell trifft dies auf eine Sammlung von Teilen „,colossaler urweltlicher Tiere" zu, die von dem Fossilsammler Albert Carl Koch (1803-1867) am Missouri in Nordamerika ausgegraben und angeboten wurde. Das Erste der Schreiben Humboldts in dieser Angelegenheit vom 9.12.1843 wird hier wiedergegeben (Abb. 6). Es war an den Kultusminister Eichhorn gerichtet und lautet wie folgt (GSTAB26. B1. 41):

\begin{abstract}
..Ich bin durch meine mineralogischen und anatomischen Freunde veranlasst ,leider!["] Ew. Excellenz wieder zu belästigen. Der Sohn eines Domänen Pächters aus der Gegend von Merseburg hat die größte aller fossilen Bestien das Missurium in Nord Amerika entdeckt und für 10000 Thaler in London verkauft. Er ist mit einem neuen Schaz von Knochen in Hamburg angekommen, die Prof. Weiss durch den kenntnissvollen Dr. Beyrich (angestellt bei dem akademischen Mineralien Cabinette) will untersuchen lassen. Es kommt also jetzt nur auf die Kosten einer Reise von 6 bis 7 Tagen nach Hamburg an. Wir flehen Ew. Excellenz um diese Munificenz, um Kosten der Hamburger Reise an! Für den Ankauf der Knochen selbst erlangen wir wohl extraordinaria vom König von 3-400 rth aber auch nicht mehr. Ich bin immer unbequem, so wie Sie, theuerste Excellenz immer nachsichtsvoll sind. - Mit innigster Verehrung Ew. Excellenz ganz gehorsamster A. v. Humboldt."
\end{abstract}

\$5 Er sah sich wohl mit seinen geologischen Vorlesungen in der Nachfolge Dechens, der Berlin 1841 verlassen hatte. Nach dem Biografisch-literarischen Handwörterbuch Poggendorffs, 1. Bd. 1863. Sp. 979. hat er von 1835 bis 1840 mit Dechen zusammen eine geol ggische Karte von Norddeutschland herausgegeben.

\$6 Johannes Miller wurde für das Mineralogische Museum besonders durch die spätere Übernahme des paläontologischen Teils der von ihm angelegten Sammlung des Anatomischen Museums wichtig. worauf sein Standbild vor dem Museum für Naturkunde hinwe'ist. 
Abb. 6. Brief Alexander v. Humboldts an Minister J. A. F. Eichhorn vom

9. 12. 1843, die Begutachtung der Sammlung von Knochenfunden betreffend. - Original im Geheimes Staatsarchiv Preußischer Kulturbesitz Berlin-Dahlem.

Fig. 6. Letter of Alexander v. Humboldt to the Secretary of Culture J. A. F. Eichhorn of 9. 12. 1843, appraisement of a collection of finds of bones. Original in Geheimes Staatsarchiv Preußischer Kulturbesitz Berlin-Dahlem.

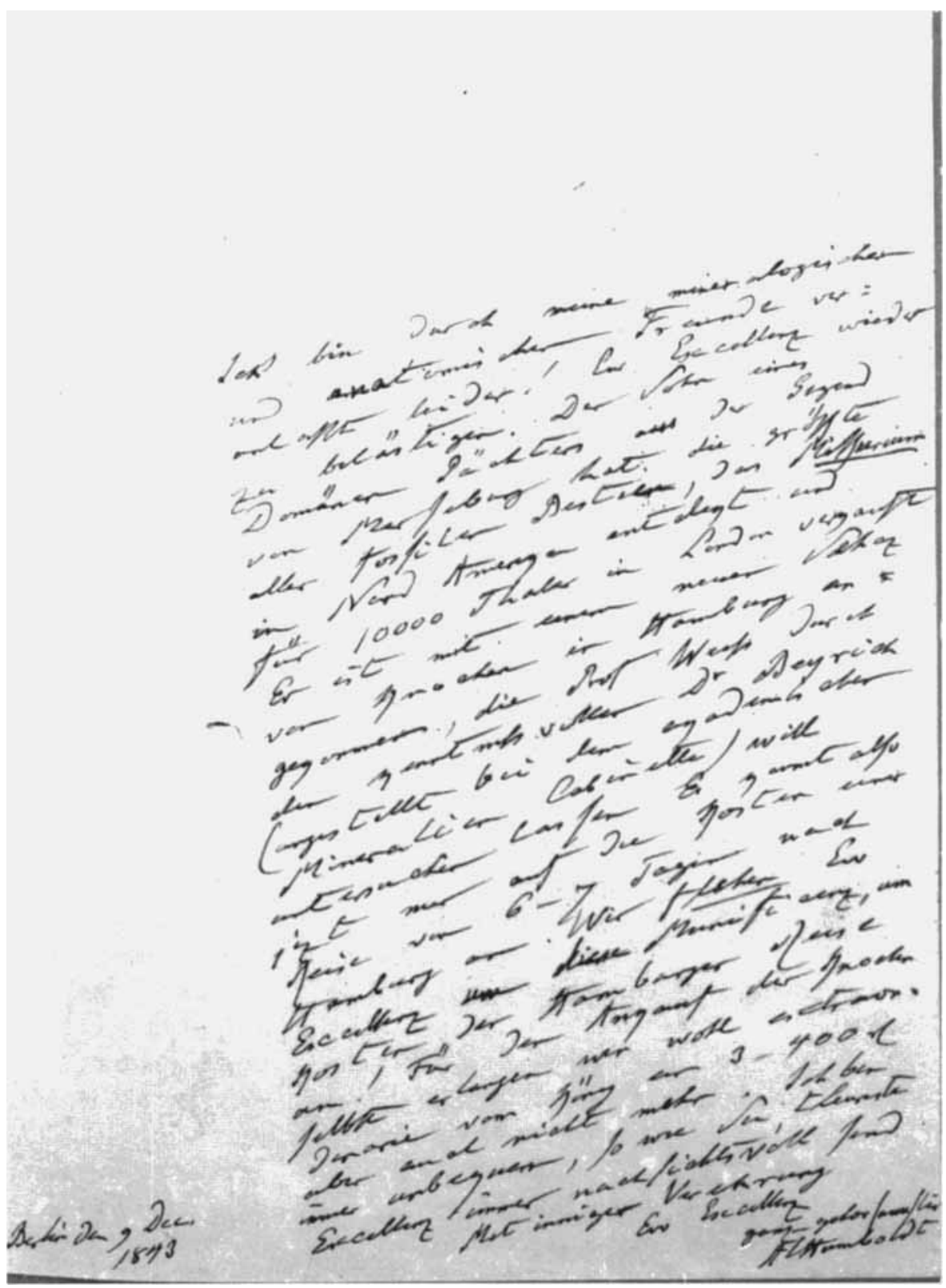

Humboldts Brief ist mit seinem Appell an die Freigiebigkeit (Munifizenz) des Ministers und der Anspielung auf den vom König zu erhaltenden, aber wohl absichtlich sehr niedrig angesetzten Kaufpreis ein kleines Beispiel seines bekannten Verhandlungsgeschicks. Auch die weiteren Schritte nahm Humboldt in die Hand und begleitete den Antrag an den König Friedrich Wilhelm IV. nochmals mit einem Schreiben vom 2. 2. 1844, dem umfangreiche Anlagen beigefügt sind (GSTAB-26, Bl. 57-90). Humboldt empfahl aufgrund von Gutachten den geforderten Kaufpreis von 2500 Talern herabzusetzen, aber auf „nicht weniger als 2200 Taler“. Eine Kabinettsorder des Königs vom 17.2.1844 genehmigte den Kauf zu diesem Betrag (GSTAB-26, Bl, 50). Weiss musste dann nach Dresden reisen, wo sich Koch aufhielt, um diesem die Zustimmung zum erniedrigten Kaufpreis abzuringen, was gelang (GSTAB 26, Bl. 55). ${ }^{57}$

\footnotetext{
${ }^{57}$ Die Akten offenbaren zahlreiche Einzelheiten, auch Komplikationen bei der Verbuchung des Kaufpreises, die schließlich durch eine weitere Kabinettsorder des Königs vom 12.10.1844 behoben werden mussten (GSTAB-26, B1. 108). - Die Darstellung der Funde von Koch bei Dietrich (1960, S. 275) betrifft im Wesentlichen den 1847 für das anatomisch-zootomische Museum angekauften Hydrarchus, die berüchtigte fehlerhafte Montage mehrerer Tierarten, die im Gießhaus der königlichen Eisengießerei ausgestellt war und erst 1884 dem Mineralogischen Museum übereignet wurde. Von der Erwerbung im Jahre 1844 scheint Dietrich keine Kenntnis gehabt zu haben, zumal das Material infolge Brandes eines Dachgeschosses des Museums für Naturkunde im 2. Weltkrieg großenteils vernichtet wurde.
} 
Nicht jede Erwerbungsabsicht verlief erfolgreich, so entgin: die große Versteinerungssammlung des Grafer Georg zu Münster (1776-1844). die nach dessem Tod für $36000 \mathrm{fl}$ Gold nach München ging Ind dort den Grundstock für die bayerische paläontologische Staatssammlung gelegt hat (G. Weiss 1989). Zwar konnte eine Sammlung von mehr als 8000 Versteinerungen. u. a. aus dem fränkischen Jura. von Carl Graf zu Münster in Osnabrück im Jahre 1845 nach Begutachtung durch Beyrich gekauft werden (GSTAB-20. Bl. 48-55. Köpke 1860: 280), jedoch war dies richt die Hauptsammlung von Georg Graf zu Münster in Bayreuth. ${ }^{58}$ Ersatzkäufe anderer, in Zusammenarbeit mit Georg Graf zu Münster entstandener Bayreuther Sammlungen. die der Ministe $r$ Eichhorn auf Empfehlung L. v. Buchs am 29.12.1846 beim König beantragte (Sammlungen Carl Haeberlein zu $9000 \mathrm{rth}$. A. Redenbacher $: \because \mathrm{u} 6000 \mathrm{fl}$ rheinisch und H. A. Braun zu 1000 rth). wurden nicht genehmigt (GSTAB-26, Eil. 64). Bei Dietrich (1960: 262) wird das Münstersche Material nur im Zusammenhang mit den Aufsammlungen von $H$. F. Emmrich mit den Worten erwähnt: ..Im Q. K. [Quenstedt-Ka:alog] ist alles als Goldfuss und Münstersche S.immlung verzeichnet. was in unserer Hauptsammlung liegt. Die Abgabe erfolgte bis $1850 . "$

Der „Verlust" der großen Münsterschen Sammlung. den A. v. Humboldt beklagte. bewog ihn, noch bevor die Ersatzkäufe scheiterten, sich für den Kauf der höchst wertvollen Versteinerungssammlung des Forstrates Heinrich Cotta (1763-1844) einzusetzen. des Gründers der (späteren) Forstakademie in Tharandt (Dietrich 1960: 271: Barthel 1980). Sie wurde im Jahre 1846 nach dem Tode Cottas erworben (GSTAB26. Bl. 118-171) und bestand vor allem aus zahlreichen fossilen Hölzern, daneben auch aus anderen paläobotanischen und -zoologischen Objekten. wie der Katalog aus dem Jahre 1845 ausweist. Aufgestellt wurde Letzterer von Bernhard Cotta. cem Sohn des Sammlers. der seit
1842 Professor für Geognosie und Versteinerungslehre an der Bergakademie Freiberg war. Auch bei dieser Sammlung gab es Schwierigkeiten bei der Aufbringung des geforderten Kaufpreises von 4000 Taler, den A. v. Humboldt in einem Brief an den König als ,mäßig“ charakterisierte (GSTAB-26, B1. 162). Nach Verhandlungen nahm der Kaufpreis schließlich einen weit niedrigeren und recht eigenartigen Betrag an, der den Rest des Dispositionsfonds des Königs für das Jahr 1845 darstellte. ${ }^{59}$

Insgesamt ist dieser Zeitabschnitt im Mineralogischen Museum durch den Ausbau der Versteinerungssammlung gekennzcichnet. Die aufblühende Paläontologie, die sich zunächst vor allem auch unter den Händen von engagierten Liebhabern und Sammlern entwickelt hatte, war inzwischen zu einer anspruchsvollen Wissenschaft geworden und hatte zugleich entsprechende Notwendigkeiten der Materialsammlung mit sich gebracht. Es war ein Prozess, der auf dem Gebiet der Mineralogie sehr viel früher abgelaufen ist. Außer den genannten Sammlungszugängen und eigenen Aufsammlungen gab es noch einige kleinere Käufe (Köpke 1860: 280), die aus dem Etat des Mineralogischen Museums erworben werden konnten, auch Geschenke waren dabei. Weitere Sammlungsbeschaffungen scheiterten, da der Staat kein Geld mehr zur Verfügung stellte, so für die Sammlung fossiler Pflanzen von H. R. Goeppert in Breslau, die am 15.12. 1842 angeboten wurde (GSTAB-26, B1. 18-37), sowie die Versteinerungssammlung Haeberlein in Pappenheim. worüber es in den Jahren 1846 und 1847 Schriftwechsel gab (GSTAB-26, u. a. Bl. 148 . $166.215){ }^{60}$

In diesen Jahren kam es in Berlin zu Bestrebungen, ein über die etablierten Institutionen hinaus wirkendes gesellschaftliches Forum zu gründen. das speziell für die Begegnung und Betätigung aller an den Geowissenschaften Interessierten gedacht war. An sich gab es bereits seit 1773 die Berliner Gesellschaft naturforschender Freunde. die neben ihren Vorstandsmitgliedern

\footnotetext{
5* Georg Graf zu Münster wurde in Schloss Langelage bei Osnabrück geboren. Er war seit 1806 bis zu seinem Tode im staatlichen Diens. Bayreuths tätig und entwickelte sich dort zu einem bedeutenden Sammler und Paläontologen. Er baute auch andere Sam nlungen auf. so die der Stadt und des Kreises (G. Weiss 1989). - Lcopold v. Buch kannte den hohen Wert der Sammlung de; Grafen Georg zu Münster und hat sie mehrfach eingehend studiert (HHMfN-4).

5) Der gezahlw: Kaufpreis betrug 3121 Taler. 51 Silbergroschen und 3 Pfennige und war in dieser Höhe durch Kabinettsorder vom 11.5. 846 (GSTAB-26. Bl. 165) genehmigt worden. Dicsen ..krummen“ Betrag hatten die Kosten einer Reise von Dr. [F. H.] Troschel in Dispositionsfonds bewirkt.

(x) An dieser Sielle beginnt in der Überlicferung der Staatsakten über das Mineralogische Museum. die bis dahin vollständig ist ( $\mathrm{Bd} 1=$ GSTAB-16 bis Bd. $7=$ GSTAB-26). durch Fehlen des Bandes 8 eine empfindliche Lücke. Sie betrifft die Jahre 1850 bis 1856 urd wird nur teilweise durch Angaben bei Köpke (1860) und Dietrich (1960) oder durch Akten über den Dispositionsfonds des Königs (GSTAB-10) u. a.. überbrückt.
} 
(maximal 12, die sog. ordentlichen Mitglieder) zahlreiche weitere Mitglieder aufnahm. Sie war ursprünglich eine Vereinigung von Liebhabern aller Richtungen der Naturkunde, die sich durch gemeinsame Bemühungen belehren wollten und hatte besonders zu Zeiten D. L. G. Karstens vor allem durch dessen Aktivität auch für die Mineralogie (im weiten Sinn) Bedeutung bekommen. Auch kamen ausgewiesene Wissenschaftler allmählich stärker hinzu, so auch Weiss, Rose und Beyrich. Diese Gesellschaft konnte aber angesichts der Entwicklungen und Spezialisierungen in den Wissenschaften die in sie gesetzten Erwartungen inzwischen nicht mehr hinreichend erfüllen. Schließlich wandte sich eine Gruppe von 13 Berliner Persönlichkeiten im Juli 1848 4 Monate nach den revolutionären Vorfällen in Berlin - mit einem Aufruf zur Gründung einer ausschließlich der Geologie gewidmeten Gesellschaft, die auch Angehörigen verwandter Wissenschaften wie Mineralogie u. a. offen stehen sollte, an die Öffentlichkeit. ${ }^{61}$ Der Aufruf hatte großen Widerhall und am Ende des Jahres 1848 kam es dann zur Gründung der Deutschen Geologischen Gesellschaft. In dieser Gesellschaft waren auch Personen aus Nachbargebieten, wie u. a. Mineralogie, zugelassen, insoweit sie zur Geologie beizutragen gewillt waren. Damit zeigte sich die Gesellschaft realistischer, als die staatlichen Institutionen, wo Mineralogie, wie zu Zeiten A. G. Werners, als übergreifender Begriff verwendet wurde. ${ }^{62}$ Als erster Präsident wurde L. v. Buch gewählt, der dies als Altersehrung auffasste. Er stand der Gesellschaft bis zu seinem Tode am 4.3.1853 vor. Sein Nachfolger wurde Beyrich, der bereits bei den Gründungsverhandlungen neben $R$. v. Carnall federführend tätig gewesen war.

Leopold von Buchs Tod war Anlass für A. v. Humboldt, sich dafür einzusetzen, dass dessen wertvolle wissenschaftliche Hinterlassenschaft der Wissenschaft durch staatlichen Ankauf erhalten blieb. Eine spezielle Akte des Staatsarchivs enthält neben umfangreichem Schriftwechsel und Gutachten einen eindringlichen Begleitbrief von A. v. Humboldts an den König (GSTAB-28, Bl. 31/2), der wesentlich zur Durchsetzung des Ankaufs beigetragen hat. In diesem Brief nennt Humboldt seinen dahingeschiedenen Freund. „den größten und weltberühmtesten Geognosten unseres Zeitalters“. Der Ankauf für das Mineralogische Museum gelang und bei Köpke (1860: 280) ist aufgelistet: „Leopold v. Buchs Sammlungen von Versteinerungen, Mineralien, Gebirgsarten, Karten und Bücher, angekauft 1853 für 15000 Thlr., die paläontologische Sammlung aus 8800 Nummern bestehend". 63

Im Jahre 1853 kam es dann noch zum Ankauf einer weiteren Sammlung von Versteinerungen, die der Privatdozent der Botanik in Berlin Hermann Karsten (1817-1908) bei Studienreisen in Venezuela und Columbien zusammengetragen hatte (Dietrich 1960: 277). Für Beyrich brachten die paläontologischen Erwerbungen einen erheblichen Aufwand an Katalogisierung und Einrangierung in die bestehende Sammlung, wodurch aber die Nutzbarkeit der immer bedeutender werdenden Bestände gesichert wurde. Außerdem hat Beyrich in den Jahren 1842 und 1843 Kartierungsarbeiten in Schlesien übernommen. Danach beschäftigten ihn für einige Zeit besonders Trilobiten, und schließlich fand er sein wichtigstes Betätigungsfeld im norddeutschen Tertiär mit seinen Versteinerungen (Beyrich 1848, 1853/4), auf das er auch später mehrfach zurückkam. Seine wissenschaftliche Tätigkeit fand im Jahre 1853 durch seine Aufnahme in die Berliner Akademie der Wissenschaften Anerkennung.

Rose hatte sich mit seinem bereits erwähnten Reisewerk über die Russlandreise, an der er 1829 als Begleiter von A. v. Humboldt beteiligt war, einen Namen gemacht (Rose 1837/42), vor allem durch die damit verbundenen zahlreichen Untersuchungen an Mineralen. In dieser Weise war Rose weiterhin tätig. Seine zahlreichen $\mathrm{Pu}-$ blikationen erschienen vorwiegend in den von

\footnotetext{
${ }_{11}$ Die 13 Initiatoren standen sämtlich in Beziehungen zum Mineralogischen Museum der Universität Berlin und sind bis auf eine Ausnahme im vorliegenden Artikel bereits erwähnt worden. Die Ausnahme ist: Ernst August Graf von Beust (1783-1859), seit 1840 als Oberberghauptmann Leiter der Berg- Hütten- und Salinenverwaltung des preußischen Staates in Berlin. - Die Gründungsväter waren in alphabetischer Ordnung: E. A. Graf v. Beust. H. Beyrich, L. v. Buch, R. v. Carnall. C. G. Ehrenberg. J. Ewald. H. Girard, A. v. Humboldt, C. J. B. Karsten, E. Mitscherlich, Joh. Müller, G. Rose und C. S. Weiss. (Kaemmel 1998).

62 Sogar noch 1865 war dies der Fall, als Beyrich zum ord. Professor für Mineralogie berufen wurde.

6.3 Ergänzend ist zu v. Buchs Nachlass zu erwähnen, dass v. Buch in früher Zeit, als D. L. G. Karsten noch lebte, mehrere von ihm geschaffene Sammlungen dem Königl. Mineralienkabinett, darunter eine Gesteinssammlung aus der Auvergne, übergeben hat (Hoppe 1999). Später, unter dem Direktorat von Weiss, hat er sich in dieser Hinsicht zunehmend zurückgehalten. obwohl er doch ehemals Weiss als Nachfolger von Karsten eindringlich empfohlen hatte. Die persönlichen Beziehungen zu Weiss hatten sich aber erheblich getrübt (Beyrich 1880), wozu wohl u. a. auch das engstirnige Verhalten von Weiss bei der Gestattung der Sammlungsnutzung beigetragen haben dürfte.
} 
seinem Freund $\epsilon$, dem Physiker J. C. Poggendorff (1796-1877). herausgegebenen Annalen der Physik und Che mie. Bevorzugt behandelte er die Minerale von umfassendem Standpunkt, um zu einer Synthese ihrer chemischen. physikalischen und kristallographischen Erscheinung zu kommen. Beispielhaft ist seine Monographie über den Quarz (Rose 1844). Schließlich überwand Rose mit seinem ..Krystallo-chemischen Mineralsystem* (Rose 1852) ${ }^{\text {ht }}$ die Einseitigkeit der früheren Mineralsysteme. sowohl des ausschließlich chemischen Systems von J. J. Berzelius. als auch des naturhisto ischen Systems von Mohs, mit dem A. G. Wemers Verfahren der Erkennung der Minerale inithilfe der äußerlichen Kennzeichen zum System erhoben wurde.

Mit den Publikationen. die Wciss weiterhin bis in sein letztes Lebensjahr (Weiss 1855) herausbrachte und die er, wenn auch nicht mehr ausschlicßlich, in den Abhandlungen der Berliner Akademie erscheinen ließ3. ergänzte er seine kristallographischen Erkenntnisse in speziellen Punkten und behandelte einzelne Minerale und Mineralgruppen. Seine früheren Höhepunkte erreichte er damit allerdings nicht mehr. An seinem Lebensende war er 46 Jahre lang als Direktor des Mineralogischen Museums tätig gewesen. eine Dauer dizr Dienstzeit, die niemals wieder von seinen Nachfolgern erreicht wurde. ${ }^{6.5} \mathrm{Im}$ Laufe dieser Zeit hatte es in den Geowissenschaften deutliche Veränderungen gegeben. So hatten sich arfangs kaum spürbare Richtungen kräftig entwickelt. woran Weiss selbst auch zum Teil aktiven Anteil hatte, die mineralogische Kristallograph e, die Geologie und die Paläontologie. Es war tin Prozess. dessen personelle Konsequenzen von Weiss bei seiner ..strengen und intoleranten [)enkungsart" (Oersted 1920: 256) anfangs nicht ichtig erkannt und akzeptiert wurden. Er war bsi seiner Berufung in der Lage gewesen. das gesamte Gebiet der damaligen Mineralogie allein $: \mathrm{u}$ vertreten und war nicht gewillt. sich von seine $r$ Alleinvertretung $z u$ trennen. Er konnte aber auch auf seinem eigenen Gebiet nicht mehr voll mit der Zeit mitgehen und hatte bis zuletzt nicht daran gedacht. ein Reflexionsgoniometer anzuschaffen, obwohl die kristallogra- phisch-mineralogische Arbeit ohne ein solches Gerät eigentlich nicht mehr denkbar war. Die Kämpfe, die Weiss mit Rose und anderen ausfocht. flauten aber in den letzten Jahren ab. Roses Toleranz hatte das Nebeneinander der beiden. charakterlich so verschiedenen Partner möglich gemacht. Den ständigen Argwohn, verdrängt zu werden, entwickelte Weiss dann bei dem viel jüngeren Beyrich als Vertreter der geologischen Paläontologic offenbar nicht.

Was im Übrigen den mündlichen Vortrag von Weiss betrifft, so urteilte sein "letzter" Schüler, sein Neffe C. E. Weiss (1880): „Sein Vortrag war bis in das letzte Semester von gleicher Lebendigkeit und Frische, sodass man oft hätte meinen können, alle die vor dem Hörcr entwickelten Gesetze seien soeben erst von ihm entdeckt worden." Auch ein anderer später Schüler, der übernächste Nachfolger von Weiss, M. Websky, würdigte anlässlich der Feier von dessen 100. Geburtstages die große Popularität des Vortrages seines Lehrers Weiss, der im Aufbau der Kristalle. allein schon von der äußeren Wahrnehmung ausgehend, die Kräfte sah, dic als letzte Konsequenz den Aufbau der Erde bewirkten, und der hoffte, in dem Kleinsten die Gesetze des Großen zu ergründen. Er fügte aber auch an, dass Weiss den eigentlichen speziellen Ausbau seines Systems anderen überlassen hat (Websky 1880). So ergab sich, dass der Ruf des Berliner Mineralogischen Museums bei aller berechtigten Würdigung der kristallographischen Leistungen von Weiss angesichts des Rückgangs von dessen Wirksamkeit schließlich wesentlich von Rose und daneben bereits auch schon von Beyrich bestimmt wurde.

Am 1. Oktober 1856 verstarb C. S. Weiss. Er befand sich auf einer Urlaubsreise mit seiner Frau im böhmischen Eger und fand dort seine Ruhestätte $^{66}$. Sein Nachfolger im Mineralogischen Museum der Berliner Universität wurde erwartungsgemäß Gustav Rose.

Die Fortsetzung vorliegender Artikelserie, ihr 5. Teil, soll den weiteren Fortgang des Mineralogischen Museums bis zum Bezug des neuen Gebäudes für die naturkundlichen Sammlungen der Universität und die damit verbundenen Auftei-

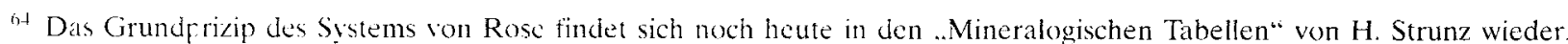
das dieser als ein späterer Nachfolger von Rose an der gleichen Einrichtung der Universität Berlin im Jahre 1942 geschaffen hat. Diese Tabelten wurden in mehreren Auflagen bis in die heutige Zeit vervollkommnet.

Nur Rose war zwar länger. 49 Jahre con 1824 bis 1873. am Mineralogischen Museum tätig gewesen, aber nur 17 Jahre als Direktor.

(6) C. S. Wciss 'vurde in Eger (heute Aš. Tschechien) heerdigt. Seine Grabstelle blieb nicht erhalten. da der Friedhof bereits lange vor dom 2. Weltkrieg in eine Grunanlage umgewandelt wurde.
} 
lung des Mineralogischen Museums in anfangs drei Abteilungen und schließlich zwei selbstständige geowissenschaftliche Einrichtungen der Universität Berlin darstellen.

\section{Danksagung}

Den Herren Professor Dr. Hans-Joachim Bautsch und Herrn Professor Dr. Martin Guntau wird für die Durchsicht des Manuskriptes und für freundliche Hinweise herzlich gedankt.

\section{Schriftenverzeichnis}

\section{Archivalien}

Vorbemerkung: In allen Zitaten aus historischen Quellen wurden Orthographie und Interpunktion unter Wahrung des Wortlautes behutsam modernisiert und Abkürzungen aufgelöst (außer im Brief Humboldts). - Die Nummerierung der Archivalien schließt sich an den 3. Teil dieser Artikelserie an. Archiv der Berlin-Brandenburgischen Akademie der Wissenschaften zu Berlin

ABBA-15 = Roses Aufnahme als Mitglied, Sign. II-III-20.

Archiv der Humboldt-Universität Berlin

AHUB-1 = Vorlesungs-Verzeichnisse und Index Lectionum der Universität.

AHUB-2 = Testamentabschrift F. Tamnau, Sign. R/S 432, 12 $\mathrm{Bl}$.

Geheimes Staatsarchiv PreuBischer Kulturbesitz Berlin-Dahlem.

Die in älteren Publikationen (z. B. Hoppe 1982) angegebenen Aktensignaturen mit dem Zusatz ZSTA Merseburg beziehen sich auf den damaligen, nach dem Ende des 2. Weltkrieges eingerichteten vorläufigen Standort der historischen preußischen Staatsakten im Zentralen Staatsarchiv Merseburg. Diese Akten befinden sich inzwischen wieder im ursprünglichen Archiv, dem heutigen Geheimen Staatsarchiv Preußischer Kulturbesitz in Berlin-Dahlem.

GSTAB-13 $=1-$ Rep. 76, Va, Sect. 2, Tit. 1, Nr. 2, vol. 3, B1. 249.

GSTAB-14 = $1-$ Rep. 76, Va, Sect. 2, Tit. 1, Nr. 2, vol. 4.

GSTAB-15 $=1-$ Rep. 76, Va, Sect. 2, Tit. 1, Nr. 2, vol. 2, Bl. 164.

GSTAB-16 $=1-$ Rep. 76, Va, Sect. 2, Tit. X, Nr. 21, Bd. 1 .

GSTAB $-17=1-$ Rep. 76, Va, Sect. 2, Tit. X, Nr. 21, Bd. 3.

GSTAB-18 $=1-$ Rep. 76, Va, Sect. 2, Tit. X, Nr. 21, Bd. 2 , B1. 9-11.

GSTAB-19=1 - Rep. 76, Vc, Sect. 2, Tit. 23, Litt. A, Nr. 18.

GSTAB-20 $=1-$ Rep. $89 \mathrm{H}$, Abt. X, Nr. 1f

GSTAB-21 $=1-$ Rep. 76, Va, Sect. 2. Tit. X, Nr. 21, Bd. 4.

GSTAB-22 = $1-$ Rep. 76, Va, Sect. 2, Tit. X, Nr. 21, Bd. 5.

GSTAB-23 $=1-$ Rep. 76, Va. Sect. 2, Tit. X, Nr. 57.

GSTAB-24 $=1-$ Rep. 76, Va, Sect. 2, Tit. X, Nr. 51.

GSTAB-25 $=1-$ Rep. 76, Va, Sect. 2, Tit. X, Nr. 21, Bd. 6.

GSTAB-26 $=1-$ Rep. 76, Va, Sect. 2, Tit. X, Nr. 21, Bd. 7.

GSTAB-27 $=1-$ Rep. 76, Va. Sect. 2, Tit. X. Nr. 58 .

GSTAB-28 =1 - Rep. 76, Va, Sect. 2, Tit. X, Nr. 73.

Handschriften-Abteilung der Staatsbibliothek Preußischer Kulturbesitz in Berlin

HASTB-3 = Nachlass C. S. Weiss, Briefe an seine Geschwister.

HASTB- $6=$ Nachlass C. S. Weiss, Manuskript „Kants Metaphysische Anfangsgründe der Naturwissenschaft" 23 Seiten.
HASTB-7 = Nachlass C. S. Weiss, Brief an das Departement für den Kultus und öffentlichen Unterricht vom 28.2. 1814.

Historische Handschriftensammlung des Museums für Naturkunde

HHMfN-1 = Bestand GnF, Tagebücher der Gesellschaft naturforschender Freunde Berlin.

HHMfN-4 = Bestand Paläontologisches Museum. Tagebücher von Leopold v. Buch.

HHMfN-5 = Bestand Paläontologisches Museum, Kollegheft von Bückling über die Vorlesung Oryktognosie von C. S. Weiss, begonnen am 8. 5.1811,242 S

HHMfN-6 = Bestand Paläontologisches Museum, Kollegheft von $\mathrm{H}$. Beyrich über die Vorlesung Geognosie von C. S. Weiss von 1833 .

Schriftgutsammlung der Technischen Universität Bergakademie Freiberg

SBAF-4 = Handschriftlicher Werner-NachlaB, Briefe an Werner, Briefe von C. S. Weiss.

\section{Literatur}

Asen, J. 1955. Gesamtverzeichnis des Lehrkörpers der Universität Berlin. I. 1810-1945. 279 pp., Harrassowitz. Leipzig.

Barthel, M. 1980. Heinrich Cotta als paläontologischer Sammler. - Fundgrube 16: 34-37.

Beyrich, E. 1837. De goniatitis in montibus rhenanis occurentibus. Dissertation. 18 pp., Berlin.

- 1848. Zur Kenntnis des tertiären Bodens der Mark Brandenburg. - Archiv für Mineralogie, Geognosie. Bergbau und Hüttenkunde (Hrsg. C. J. B. Karsten \& H. v. Dechen) 22: 246-254.

- 1853/1854. Die Conchylien des norddeutschen Tertiärgebirges. - Zeitschrift der deutschen geologischen Gesellschaft 5: $273-258,6$ : 408-500, 726-781.

- 1880. Gedenkworte am Tage des hundertjährigen Geburtstages von Christian Samuel Weiss. - Zeitschrift der deutschen geologischen Gesellschaft 32: XXII-XXIV.

Biermann, K.-R. 1960. Aus den Anfängen der wissenschaftlichen Laufbahn Franz Neumanns, des Begründers der mathematischen Physik in Deutschland. - Forschungen und Fortschritte 34: 97-101.

Böhme, G. 1967. Geschichte der naturwissenschaftlichen Sammlungen in Meiningen. - Südthüringer Forschungen 2: $1-119$.

Dietrich, W. O. 1960. Geschichte der Sammlungen des Geologisch-Paläontologischen Instituts und Museums der Humboldt-Universität zu Berlin. Ein Beitrag zur Paläontologie-Geschichte. - Berichte der Geologischen Gesellschaft der DDR 5: 247-289.

Emmrich, H. 1839. De trilobitis. Dissertation. 56 pp., Nietack, Berlin.

Ewald, J. 1837. De crystallis duorum axium opticorum. Dissertation. 27 pp., Berlin.

Fischer, E. 1963. Christian Samuel Weiss und die zeitgenössische Philosophie (Fichte, Schelling). - Forschungen und Fortschritte 27: 141-143.

Fröbel, F. 1862. Gesammelte pädagogische Schriften, hrsg. von R. Lange. Band 1.1. Autobiografie und kleinere Schriften. X, 542 pp, Enslin, Berlin.

Girard, H. 1840. De basaltis eorumque et vulcanorum rationibus. Dissertation. 52 pp., Schlesinger. Berlin.

Groth, P. 1926. Entwicklungsgeschichte der mineralogischen Wissenschaften. VI, 261 pp., Springer, Berlin.

- 1954. Die wissenschaftliche Bedeutung Friedrich Tamnau's. - Neues Jahrbuch für Mineralogie, Monatshefte. 69-72. - Vorwort von Herausgeber H. S[chneiderhöhn].

Haarmann, E. 1942. Lose Blätter aus der Geschichte der Geologie. Mitteilungen des Geologen-Archivs. - Geologische Rundschau 33: 84-207. 
Hauchecorne. W. 1397. Heinrich Ernst Berrich. - Jahrbuch der Königl. PreatBischen geologischen Landesanstalt und Bergakademie 17 (1896): CII-CXXXVIII.

Haüv. R. J. 1801. Traité de minéralogie. + rol. et alas. T.1 LVI, 494 pp.. T..? IV. 617 pp. T.3 IV. 588 pp.. T.t VI. 592 pp. T.5 VIII. 10 pp. LXXXVI pl.. Louis. Paris.

- 1804/1806/1810. _ehrbuch der Mineralogie (Hrsg. D. L. G. Karsten) + Texibände und Tafelband. Bd. 1. XX. 611 pp. (1804). Bd. 2. XX. 723 pp. (1804). Bd. 3 XXXII. 686 pp. (1806). Bd. 4. TIII. 734 pp. (1810). Bd. 5. Tafeln (1810). Reclam. Paris u $\mathrm{xd}$ Leipzig. (Ubersetzer waren C. S. Weiss und K. J. B. Kirsten zu gleichen Teilen. C. S. Weiss war Mitherausgeber ab $\mathrm{Bd}$. 3).

Helms. J. 1997. Au zust Heinrich Ernst Beyrich als Paläontologe. - Zeitschrift der deutschen goologischen Gesellschaft 148: $291-308$.

Hoffmann. F, 183\%. Phrsikalische Geographie. Vorlesungen gehalten an de Universitä zu Berlin in den Jahren 1834 und 1835 . 1. Bu. XL. 620 pp.. 2. Bd. VIII. 596 pp.. Nicolai. Berlin.

Hoppe. G. 1977. Enst Florens Friedrich Chladni. Zum 150. Todestag des Fegründers der Meteoritenkunde. - Chomie der Erde 3i: 2\$9-262.

- 1982. Christan Samuel Weiss und das Berliner Mineralogische Museum. - Wissenschaftliche Zeitschrift der Humboldt-Dniversitit Berlin. Mathematisch-naturwissenschaft. liche Reihe 31: 245-254.

- 1983. Fin Museumsdiebstahl vor $1+4$ Jahren. - Ncue Museumskunde. B zrlin 26. S. 20.

1989. Martin Hinrich Klaproth (1743-1817) als Mineralchemiker unc Mineralsammler. - Aufschluss 40. $201-214$

- 1987a. Das Königliche Mineralienkabinett in Berlin. Vor läufer des Mireralogischen Museums der Berliner Universität. - Nele Museumskunde 30: 295-307.

- 1987b. Die Meleoritensammlung E. F. F. Chladnis. - Dic Sternc, Leipzig. 63: 315-.329.

- 1998. Zur Geschichte der Geowissenschaften im Museum für Naturkund: zu Berlin. Teil 1. Aus der Vorgeschichte his zur Gründung der Berliner Bergakademic im Jahre 1770. - Mitte lungen aus dem Museum für Naturkundo der Humboldt-Universität in Berlin. Geowissenschaftliche Reihe 1: $5-19$

- 1999. Zur Geschichte der Geowissenschaften im Museum für Naturkunde zu Berlin. Tcil 2. Von der Gründung der Bergakademie zur Gründung der Universität 1770-1810. - Mitteilungen aus dem Muscum für Naturkunde der Humboldt-Cniversität in Berlin. Geowissenschattliche Reihe 2: 3-24

- 2000. Zur Ges hichte der Geowissenschaften im Museum für Naturkunde zu Berlin. Teil 3. Von A. G. Werner und R. J. Haty zu C. S. Weiss - Der Weg von C. S. Weiss zum Direktor des Mineralogischen Museums der Berliner Universität. - Mitteilungen aus dem Museum für Naturkunde der H imboldt-Lniversitat in Berlin. Geowissenschaftliche Re he 3: 3-25.

2001: Gustav Fose. der Reisebegleiter von A. r: Humbold 1829. In DA: ML-Expeditions- und Konferenzbuch ...Auf den Spuren Alexander von Humboldts in Russland" (Hrsg. K. Aranda. A. Förster und (h. Suckow). Im Druck.

Hoppe. G. \& Barthel. M. 1986: Der Beitrag Alexander von Humboldts zır Entwicklung der geowissenschaftlichen Sammlungen der Berliner Lniversität. - Abh. Akad. Wiss. DDR. : Hath-Nat.-Techn. für 1985. 2 N: 92-47. Auch in: A. $\because$ Humboldt-Ehrung in der DDR. Berlin: $99-105$.

Kaemmel. T. 10ys. Kurzbiographien der dreizehn Gründungsväter der Deutschen Geologischen Gesellschaft. Geohistorische Blätter 1: $55-70,97-103$.

Kant. I. 1786. Metaphysische Antangsgründe der Naturwissenschaft. Rig?.

Kayser. E. 1834. Beschreibung der Mineraliensammlung des Herm Medizinalrath Bergemann zu Berlin. X. $501 \mathrm{pp}$. Nauck. Berlin.
- 1834/5. De cyclo quodam legum duodecim, secundum quas crystalli generum Feldspathi familiae singulariorum geminatim conjunctae inveniuntur. Dissertation. Berlin 1834. - Deutsche Übersetzung: Über einen Cyclus von zwolf Zwillingsgesetzen, nach welchen die Krystalle der cin- und eingliedrigen Feldspathgattungen verwachsen. Annalen der Physik und Chemie (Hrsg. J. C. Poggendorff) 34 (1835): $109-129,301-319$.

Klöden. K. F. v. 1874. Jugenderinnerungen (Hrsg. M. Jähns). VIII. 532 pp. Glunow. Leipzig.

Köpke. R. 1860. Dic Gründung der Königlichen FricdrichWilhelms-Universitat zu Berlin. VI, 300 pp. Schade, Berlin. - Hierin: [Rose. G. ] Das mineralogische Muscum: $279-282$

Krusch. P. 1904. Die Geschichte der Bergakademie zu Berlin ron ihrer Gründung im Jahre 1770 bis zur Neueinrichtung im Jahre 1860. 54 pp. Verlag der Kgl. Geol. Landesanstalt und Bergakademie. Berlin.

Langer. W. 1983. Karl Wilhelm Nose. Pionier der mineralogisch-geologischen Siebengebirgs-Erforschung. - Rheinische Heimatpflege. N. F. 20: 257-260.

Lenz. M. 1910. Geschichte der königlichen Friedrich-Wilhelms-Universität zu Berlin. Bd. 1. Gründung und Ausbau. XV. 644 pp. Bd. 2. 1. Ministerium Altenstein. IX. 514 pp. Bd. 2. 2. Auf dem Wege zur deutschen Einheit im Neuen Reich. XI1. 512 pp.. Bd. 3. Wissenschaftliche Anstalten. Spruchkollegium, Statistik. VIII, 536 pp., Bd. 4. Urkunden. Akten. Briefe. XII, 602 pp., Verlag des Waisenhauses. Halle.

Mitscherlich. E. 1820. Über dic Krystallisation der Salze, in denen das Metall der Basis mit zwei Proportionen Sauerstoff verbunden ist. - Abhandlungen der Akademie der Wissenschaften zu Berlin für 1818/19, Physikalische Klasse. Berlin. 427-437. - Vorgetragen am 9. 12.1819.

- 1837. Bestimmung der Ausdehnung krystallisirter Körper durch dic Wärme. - Berichte dor Berliner Akademie der Wissenschaften. 69-71. (Sitzung vom 11.5. 1837).

Mitscherlich. A. (Hrsg.) 1896. Gesanmelte Schriften von Eilhard Mitscherlich. Lebensbild, Briefwechsel und Abhandlungen. XIV. 678 pp., Mittler, Berlin.

Mohs. F. 1822/4. Grund-Riß3 der Mineralogie. 2 Bde. XII, 604 pp. und XXXVI. 730 pp. Arnold, Dresden

- 1829/30. Die Einwürfe des Herrn Prof. Weiss gegen die naturhistorische Methode der Mineralogie. - Zeitschrift für Physik und Mathematik (Hrsg. A. Baumgartner und A. v: Ettingshausen) 6: 385-433, und 7:1-47.

Naumann. K. F. 1828. Elcmente der Mineralogie. Leipzig. Ab 10. Aullage. 1877. von F. Zirkel herausgegeben.

- 1830. Lehrbuch der reinen und angewandten Krystallographic. 2 Bde. X. 516 pp. und VIII, 556 pp.. Brockhaus. Leipzig.

Neumann. F. E. 1823. Beilräge zur Kristallonomic. 152 pp., Mittler. Berlin und Posen.

- 1826. De lege zonarum. Disscrtation. Berlin.

Neumann. L. 1904. Franz Neumann. Erinnerungsblätter von seiner Tochter. XII. 463 pp.. Mohr, Tübingen und Leipzig.

[Nose. C. W.] 1808. Mineralogische Studien über die Gebirge am Niederrhein nach der Handschrift eines Privatisirenden herausgegeben von J. J. Nöggerath. 276 pp., Frankfurt a. $\mathrm{M}$.

Orsted. H. C. 1920. Correspondance de H. C. Örsted avec divers savants. Publiée par M. C. Harding. Tome 1. X: 367 pp. Aschehoug. Copenhague.

Paulitsch. P. 1970. Hessische Mineralien. - Aufschluss 21: $23-27$.

Quenstedt. F. A. 1835. Darstellung und Entwicklung der Krystallverhältnisse mittelst einer Projektionsmethode. Annalen der Physik und Chemie (Hrsg. J. C. Poggendorlf) 34: 503-518. 651-661.

- 1836. De notis nautilearum primariis. Dissertation. Berlin.

- 1852. Handbuch der Pctrefaktenkunde. Laupp, Tübingen. (2. Autl. 1867. VIII, 982 pp.). 
Quenstedt, W. 1941. Friedrich August Quenstedt. Mineraloge, Geologe und Paläontologe. 1809-1889. - Schwäbische Lebensbilder 2: 377-390.

Rammelsberg. [K. F.] 1880. Gedenkworte am Tage der Feier des hundertjährigen Geburtstages von Christian Samuel Weiss. - Zcitschrift der deutschen geologischen Gesellschaft 32: XXI-XXII.

Raumer. K. G. v. 1866. Karl von Raumers Leben, von ihm selbst erzählt. VIII, 344 pp., Liesching, Stuttgart.

Rose, G. 1820. De sphenis alque titanitae systemate crystallino. Dissertation. $26 \mathrm{pp}$., Berlin. (Verteidigung am 9. 12. 1820).

- 1825. Über die in den Meteorsteinen vorkommenden krystallisierten Mineralien. - Annalen der Physik und Chemic (Hrsg. J. C. Poggendorff) 4: 173-192.

- 1833. Elemente der Krystallographie, nebst ciner tabellarischen Übersicht der Mineralien nach den Krystallformen. VI. 173 pp., 10 Taf., Mittler, Berlin. (2. Aufl. 1838, XII, 175 pp., 10 Taf.; 3. Aufl. Hrsg. A. Sadebeck, 1873, VI, 181 pp.).

- 1837/1842. Mineralogisch-geognostische Reise nach dem Ural, dem Altai und dem Kaspischen Meere. 2 Bde. (1. Band: Reise nach dem nördlichen Ural und dem Altai. XXXI, 641 pp.; 2. Band: Reise nach dem südlichen Ural und dem Kaspischen Meere, Übersicht der Mineralien und Gebirgsarten des Ural). XVII, 606 pp., Sander, Berlin.

- 1837a. Über die Bildung des Kalkspaths und Arragonits. -- Annalen der Physik und Chomie (Hrsg. J. C. Poggendorff). 42: $353-367$.

- 1844. Uber das Kristallsystem des Quarzes. - Abhandlungen der Akademie der Wissenschaften zu Berlin für 1844. Physikalische Abhandlungen, Berlin: 217-274. - Vorgetragen am 25.4. 1844. (Auszug und Teilabdruck in Annalen der Physik und Chemie, Hrsg. J. C. Poggendorff, 62 , 1844: 325-337).

- 1852. Das krystallo-chemische Mineralsystem. VI, 156 pp. Engelmann, Leipzig.

Schlotheim. E. F. v. 1820. Die Petrefaktenkunde auf ihrem jetzigen Standpunkte durch die Beschreibung seiner Sammlung versteinerter und fossiler Überreste des Thierund Pflanzenreichs der Vorwelt erläutert. LXII, 437 pp., Becker, Gotha.

Schuster, J. 1922. Aus unveröffentlichten Dokumenten zur Geschichte der Mineralogie, Geologie und Paläontologie. Historische Miniaturen. I. Christian Samuel Weiß und die Naturphilosophie. II. Christian Samuel Weiß' kristallographisches System und René Just Haüy. Mit einem unveröffentl. Bricf von Oken. III. Ernst Fricdrich von Schlotheim und der Übergang seiner Petrefaktensammlung an den preußischen Staat. In Degering. H., Christ, K. \& Schuster, J.: Aus der Handschriftenabteilung der Preußischen Staatsbibliothek. Breslauer, Berlin: 87-109.

Steffens, H. 1844. Was ich erlebte. Bd. 8: 268-269. Max, Breslau.

Strunz, H. 1970. Von der Bergakadomie zur Technischen Universität Berlin, 1770 bis 1970. 151 pp., Technische Universität Berlin.

Websky, M. 1880. Gedenkworte am Tag der Feier des hundertjährigen Geburtstages von Christian Samuel Weiss. Zeitschrift der deutschen geologischen Gesellschaft 32: III-IV.

Weiss. C. E. 1860 . De indaganda quarzi systematis evolutione et de amplificandis evolutionibus crystallographicis. Pars prior. 31 pp., Büxenstein, Berolini. (Phil. Diss. Halle).

Weiss, [C. E.] 1880. Gedenkworte am Tag der Feier des hundertjährigen Geburtstages von Christian Samuel Weiss. Zeitschrift der deutschen geologischen Gesellschaft 32: $\mathrm{VI}-\mathrm{XXI}$
Weiss, C. S. 1809. De indagando formarum crystallinarum charactere geometrico principali dissertatio. - De charactere geometrico principali formarum crystallinarum octacdricarum pyramidibus rectis basi rectangula oblonga commentatio. 49 pp., Tauchnit\%, Lipsiae.

- 1815. [Briefliche Mitteilung]. Taschenbuch für die gesammte Mineralogie (Hrsg. C. C. Leonhard) 9. 1: 296-301.

- 1818. Übersichtliche Darstellung der verschiedenen naturlichen Abtheilungen der Krystallisationssysteme. - Abhandlungen der Akademie der Wissenscharten zu Berlin für 1814/15, Physikalische Klasse: 289-336. - Vorgetragen am 14.12. 1815 .

- 1819a. Krystallographische Fundamentalbestimmung des Feldspathes. - Abhandlungen der Akademie der Wissenschaften zu Berlin für 1816/17. Physikalische Klasse: 231-285. - Vorgetragen am 13.6.1816.

- 1819b. Über eine verbesserte Methode für die Bezeichnung der verschiedenen Flächen eines Krystallisationssystems: nebst Bemerkungen über den Zustand von Polarisierung der Seiten in den Linien der krystallinischen Structur. - Abhandlungen der Akademie der Wissenschaften zu Berlin für 1816/17. Physikalische Klasse: 287-336. - Vorgetragen am 20. 2. 1817.

- 1820. Betrachtung der Dimensionsverhältnisse in den Hauptkörpern des sphäroedrischen Systemes und ihren Gegenkörpern, in Vergleich mit den harmonischen Verhältnissen der Töne. - Abhandlungen der Akademic der Wissenschaften zu Berlin für 1818/19. Physikalische Klasse: $227-241$. - Vorgetragen am 22. 10. 1818 .

- 1822a. Über mehrere neubeobachtete Krystalllächen des Feldspathes und die Theorie seines Krystallsystems im Allgemeinen. - Abhandlungen der Akademic der Wissenschaften zu Berlin für 1820/21. Physikalische Klasse: 145-184. - Vorgetragen am 30.11. 1820.

- 1822b. Über das Krystallsystem des Gipses. - Abhandlungen der Akademie der Wissenschaften zu Berlin für 1820y 21, Physikalische Klasse: 195-222. - Vorgctragen am 26. 7. 1822 .

- 1825. Grundzüge der Theorie der Sechsundsechskantner und Dreiunddreikantner, entwickelt aus den Dimensionszeichen für ihre Flächen. - Abhandlungen der Akademic der Wissenschaften zu Berlin für 1822/23. Physikalische Klasse: 217-264. - Vorgetragen am 13.2. 1823.

- 1827. Über einige gcognostische Punkte bei Meilien und Hohenstcin. - Archiv für Bcrgbau und Hüttenkunde (Hrsg. C. J. B. Karsten) 16:3-16.

- 1829. Das Mineralsystem des Prof. Weiss; nebst ciner Einleitung über die Bildung des natürlichen Systems. mit besonderer Rücksicht auf das naturhistorische des Herrn Mohs. - Archiv für Mineralogie, Geognosic. Bergbau und Hüttenkunde (Hrsg. C. J. B. Karsten) 1: 5-28.

- 1830. Antwort des Prof. Weiß auf des Herrn Prol. Mohs in der Zeitschrift für Physik und Mathematik erschienenen Artikel. - Archiv lür Mineralogic, Geognosie. Bergbau und Hüttenkunde (Hrsg. C. J. B. Karsten) 2: 3-37.

- 1832. Über das Staurolithsystcm, als abgeleitet aus dem regulären Krystallsystem. - Abhandlungen der Akademie der Wissenschaften zu Berlin für 1831. Physikalische Klasse: 313-336. - Vorgetragen am 24.11.183i.

- 1834. Vorbegriffe 7u einer Cohäsionslehrc. Erste Abtheilung. - Abhandlungen der Akademie der Wissenschaften zu Berlin für 1832. Physikalische Klasse: 57-83. - Vorgetragen am 28.6.1832. - (Fortsetzung nicht erschienen).

- 1855. Krystallographische Bemerkungen über das shomboedrische System. - Monatsberichte der Berliner Akademie der Wissenschaften: 7-9 und 90-97. - Vorgetragen am 8.1. und 5.2.1855.

Weiss, G. 1989. Graf Georg zu Münster (17. Febr. 1776-23 Dez. 1844). - Aufschluss 40: 403-411. 